\title{
Five Crossroads on the Way to Basic Income. An Italian Tour
}

\author{
Ugo Colombino ${ }^{1}$
}

Received: 4 March 2015 / Accepted: 23 June 2015 / Published online: 14 July 2015

(C) Società Italiana degli Economisti (Italian Economic Association) 2015

\begin{abstract}
The current Italian income support policies are defective with respect to efficiency and equity. A reform must face five crucial choices: universal vs. categorical policies; transfers vs. subsidies; unconditional vs. means-tested policies; coverage; flat vs. progressive tax rules. Using a microeconometric model and a social welfare methodology, we simulate — under fiscal neutrality and market equilibrium - the effects of 30 policies obtained from three basic types: conditional basic income, unconditional basic income and wage subsidies. The alternative reforms are evaluated according to four different social welfare criterion: the pure utilitarian and three different versions of a Gini-type social welfare function. The pure utilitarian criterion favours reforms based on a wage subsidy or a combination of wage subsidies and transfers. The Gini-type criteria favour unconditional transfers or combinations of wage subsidies with unconditional transfers. Most of the reforms turn out to be preferable to the current system: the choice set available for selecting a "best" reform given different criteria is very large.
\end{abstract}

Keywords Income support mechanisms - Basic income - Guaranteed minimum income $\cdot$ Wage subsidies · Tax reform simulation

JEL Classification $\mathrm{H} 31 \cdot \mathrm{H} 21 \cdot \mathrm{C} 25$

$\bowtie \quad$ Ugo Colombino ugo.colombino@unito.it

1 Dipartimento di Economia e Statistica "Cognetti De Martiis", University of Turin, Lungo Dora Siena 100, 10153 Turin, Italy 


\section{Introduction}

In this paper, we explore the feasibility and the optimal features of a universal policy of income support in Italy. Abundant analyses and empirical evidence produced during the last two decades have documented the deficiencies, with respect to both efficiency and equity goals, of the Italian income support policies. ${ }^{1}$ Three critical points concern the contingent interventions, e.g. unemployment benefits and Cassa Integrazione: (a) they are limited to certain occupational sectors and types of contract, thus generating social exclusion and processes of the insider-outsider type, (b) they are more aimed at preserving the job rather than the worker's income and opportunities, thus discouraging the labour reallocation from unprofitable jobs to more promising ones, (c) some interventions go through a bargaining process involving firms, unions and local or central authorities, thus adding more sources of potential inequities. As to the structural anti-poverty interventions (e.g. Assegno Sociale, Assegno per il Nucleo Familiare, Social Card etc.), they are mainly aimed at supporting elderly or disabled people or low-income households with mean-tested/conditional/categorical benefits. Embodied in the personal income taxation system there are tax credits and child benefits that can also be classified as anti-poverty policies. It has been observed, however, that the design of the mean-tested tax credits and child benefits create distortions and bad incentives for labour market participations of married women (Colonna and Marcassa 2012). None of the above policies is universal: for example, Cassa Integrazione and Assegno per il Nucleo Familiare are limited to wage employees. A serious attempt to rationalize the income support policies in Italy took place in the second half of the 90s. In 1997 a governmental commission (Commissione Onofri) recommended the introduction of a universal minimum income mechanism both to contrast poverty and to favour the mobility of labour between firms and across occupations, as a crucial element for a new general design of the Italian welfare state (Onofri 1997). In 1998, Reddito Minimo di Inserimento (RMI)—a limited form of minimum income support-was introduced in a number of municipalities in order to test its organizational feasibility. However, in 2001 the Government decided to put an end to the RMI "experiment". Meanwhile a partial constitutional reform had transferred the responsibility for social assistance from the central government to the regional authorities. This process, together with the unfavourable macroeconomic international conditions and a very high public debt, during the following decades discouraged further attempts to consider minimum income policies as a universal and nation-wide institution, despite the recommendations on the part of the European Community. ${ }^{2}$ Since 2008, however, the "Great Recession" has put much stress on the current policies, confirming their shortcomings and stimulating a debate on the need for a reform. In 2014, $52 \%$ of the employed under 25 has a precarious

1 Among others: Negri and Saraceno (1996), Onofri (1997), Boeri and Perotti (2002), Baldini et al. (2002), Aaberge et al. (2004), Sacchi (2005), Berton et al. (2009), Colonna and Marcassa (2012), Ferrera et al. (2012), Baldini and Toso (2013), Saraceno (2013) and Perazzoli (2014).

2 Bin Italia (2012), CIES (2012) and VV. AA. (2014) provide surveys of policies adopted by some local authorities and organizations. See also Busilacchi (2013), Bin Italia (2012) and Perazzoli (2014) for surveys of basic income policies in Europe. 
job (26.5\% in 2000). From 2008 to 2014, the unemployment rate increased from 6.7 to $13.0 \%$. In the same period, the relative (absolute) poverty in Italy increased from 11.3 (4.6) to 12.6 (7.9). The Italian system has been labelled Flex-insecurity (Berton et al. 2009), since it appears to suffer from the deficiencies of a deregulatedand yet inefficient-labour market and from the lack of a universal safety net. In 2012 and 2015 the Italian Parliament introduced changes in the income support policies for the unemployed. The reforms make some modest moves in the direction of universalism: the overall system, however, is still largely based on categorical principles. $^{3}$

The Italian scenario is part of a wider picture. Besides the effects of the "Great Recession", high unemployment rates and job insecurity are more fundamentally a byproduct of automation and globalization. Along with large potential gains, these processes also bring massive reallocations of activities, jobs and labour. There is evidence that the gains from automation and globalization end up in just a few hands and are likely smaller than they might otherwise be unless efficient redistribution mechanisms are implemented (Spence 2011; Standing 2012; Sachs and Kotlikoff 2012; Cowen 2013; Krugman 2013; Hughes 2014; Marchant et al. 2014; Brynjolfsson and McAfee 2014). The increasing need for redistribution stemming from globalization and technological progress is also the focus of the so-called "compensation thesis" (Rodrik 1998; Brady et al. 2005). Failing to design efficient means of redistributing the benefits may prevent some of the potential benefits from materializing.

There are several types of income redistribution and maintenance policies, and the terminology used when discussing them is sometimes confusing. Guaranteed minimum income or minimum income guarantee policies envisage transfers that guarantee a minimum level of income. The transfers may be subject to some selection criterion (for example, only single mothers under age 25) or condition (such as means testing or work requirements). If there are no selection criteria, the policy is universal, and if there are no conditions, it is unconditional. The negative income tax guarantees a minimum level of income, but the size of the transfer depends on the person's own income (means testing). In some implementations, negative income tax-like mechanisms might include a work requirement (such as requiring a minimum number of hours of work). There are also non means-tested transfers that are subject to behavioral conditions, such as sending children to school: these are referred to as conditional cash transfers. Unconditional basic income envisages unconditional transfers. When unconditional basic income is also universal (e.g. given to every citizen), it is sometimes called citizen income.

The literature on welfare systems has suggested various typologies. EspingAndersen (1990) addresses the general structure of welfare systems and defines three ideal types (liberal, corporatist and social-democratic). Italy's welfare, together with Germany's and France's, is classified as corporatist, i.e. a system mainly based on contributory mechanisms and occupational-professional categorizations. However, both France and Germany, differently from Italy, do have a universal income

\footnotetext{
${ }^{3}$ A few proposals for the introduction of a means tested guaranteed minimum income have are available, e.g. Alleanza contro la povertà in Italia (2014) and Mistero del Lavoro e delle Politiche Sociali (2014).
} 
support policy. Frazer and Marlier (2009) analyze more specifically the income support mechanisms and classify the European countries into four groups based on the prevalence of universalistic vs. categorical policies, the eligibility criteria and the generosity of the benefits. Based on analogous attributes, Jansova and Venturini (2009) define seven ideal types as fuzzy sets and compute scores that measure the degree to which the European countries belong to alternative types. The latter two analyses show that Italy_although belonging to the same corporatist type-adopt a very different income support policy with respect to France and Germany where, besides standard unemployment insurance, universal (means-tested) income support mechanisms are active since long. However, despite large differences in institutions, political constraints, combinations of monetary and in-kind benefits and levels of generosity, it is fair to say that, up to the early 90 s, the social assistance policies of most industrialized countries were close to a more or less explicit means-tested guaranteed minimum income, with a very high implicit benefit reduction rate (the rate at which benefits are withdrawn as the recipient's own earnings increase). During the last two decades, automation, globalization and their implications of the reallocation of jobs and skills, inflated the number of people in need of assistance and, in turn, the volume of social expenditure. The ageing of the population and the relative restriction of the labour force in developed countries made even more difficult the sustainability of the current social policies. Poverty-trap, stigmatization and marginalization problems associated with means-tested policies emerged as well. Many countries responded by moving toward less protection, and/or greater selectivity, and/or more sophisticated means-testing and eligibility conditions: reducing guarantees, increasing work incentives (through tax credits, wage subsidies, and behavioral requirements as a condition for receiving benefits), and narrowing the segment of the population qualifying for income support. While such policies have been partially successful for managing short-run income support programs and moderating poverty trap effects, it remains to be seen whether they meet the goal of implementing efficient mechanisms of global redistribution. Economists, social scientists and politicians divide into two positions: some (the majority) tend to support the direction that has so far prevailed in practice; others suggest universal and unconditional policies as the true solution (e.g. Standing 2011; Atkinson 2015).

This paper aims at providing an empirical contribution to the debate, with focus on Italy. While in most European countries universal income support is- to some extentalready implemented, and the critical issue is how to overcome the deficiency of the classical welfare policies by moving either toward more sophisticated means-testing and behavioural conditioning or towards unconditional mechanisms, the specificity of Italy (and Greece) is the absence of a universal income support policy. We present an exercise in designing a universal income support mechanism that replaces the actual categorical policies and maximizes a given social welfare function subject to a public budget constraint. In principle, the formulation of the problem is provided by optimal taxation theory (e.g. Saez 2001, 2002). However, instead of looking for an analytical solution we adopt a computational-empirical approach. Namely, we use a microeconometric model and a social welfare methodology in order to explore and 
evaluate various alternatives mechanisms. ${ }^{4}$ Adopting a microeconometric model that accounts for behavioural responses is appropriate since the crucial issues, when evaluating income support policies, concern the incentives upon household choices and their interaction with efficiency and distributional effects. In Sect. 2, we illustrate, with references to the relevant theoretical and empirical literature, the alternative possible attributes of a mechanism of income support along five dimensions. This analysis produces 30 alternative reforms that are described in detail in Sect. 3 and in the Appendix. In order to evaluate the reforms, we adopt a procedure that requires many steps. First, in Sect. 4, we develop a microeconometric model of household labour supply, based on a constrained utility maximization framework. Second, the model permits to simulate the new labour supply choices of household members when facing the new budget constraints induced by the alternative reforms. Therefore, for each alternative reform and for each household, we produce relevant results such as hours worked, income, taxes paid, benefit received etc. and ultimately the new attained utility level. The simulation is performed subject to two constraints: market equilibrium and fiscal neutrality (Sect. 5.2). More precisely, we endogenously identify the reform's parameters that guarantee to satisfy the constraints. Third, the final evaluation is obtained by aggregating the (money-metric and interpersonally comparable) utility levels into four alternative social welfare functions: the pure utilitarian, the Gini Social Welfare (GSW) and two variants of the GSW augmented with poverty indexes (Sect. 5). Section 6 presents and comments the behavioural, fiscal and social welfare results. We also performs an analysis that allows us to identify the contributions of the reforms' attributes on social welfare and its efficiency and equity components. Section 7 contains the conclusions.

\section{Five Crossroads}

In illustrating the motivations, the methods and the results of our exercise, we will refer to five issues that emerge as crucial in the analysis of reforms, whether hypothetical or implemented.

\subsection{Universal vs. Categorical Policies}

The background motivation for addressing this issue lies in the recent advances in technology and in globalization processes. The impact of those processes on jobs and skills, the sharp increase in income and wage inequality, and the marked fall in labor's share in national income since the 1990s suggest that the implementation of universal mechanisms of redistribution might be required. In principle, both automation and globalization can bring universal gains. In practice, there are winners and losers. How large the benefits and costs are and how they are distributed, depends on the

\footnotetext{
4 The approach is close to Fortin et al. (1993) and Aaberge et al. (2004). More complex exercises, where a social welfare index is maximized with respect to the parameters of the tax rule, within a class of piecewiselinear rules, are presented by Aaberge and Colombino (2006, 2012, 2013) and Blundell and Shephard (2012). For a survey of microeconometric and microsimulation models in tax-benefit reforms evaluation, see Aaberge and Colombino (2014).
} 
redistribution mechanisms. The empirical evidence suggests that the current scenario envisages just a few big winners but many more moderate to big losers (e.g. Cowen 2013). According to many authors, a universal redistribution mechanism might be the appropriate policy. ${ }^{5}$ One of the motivations for moving towards universal rather than categorical policies is the increasing difficulty in defining precise and stable categorizations of the population in its relationship with the labour market. From a more limited perspective, we investigate whether universalistic reforms are feasible with respect to the public budget constraint and more desirable-according to a social welfare criterion-than the current Italian categorical policies.

\subsection{Transfers vs. Subsidies}

Most numerical simulations done with the model of Mirlees (1971) suggest as an optimal system a tax-benefit schedule with a lump-sum transfer, very high marginal tax rates on low income and almost constant marginal tax rates on average and high income. This scenario seems to have inspired many reforms (implemented or discussed) in the three decades 1970-1980-1990. A second scenario emerges at the end of the 90s, with contributions (e.g. Diamond 1998; Saez 2001, 2002) that make Mirlees' model more amenable to econometric applications, e.g. Immervoll et al. (2007), Haan and Wrohlich (2007) and Blundell et al. (2009). A frequent result emerging from these empirical exercises-based on Saez (2002)'s theoretical model—is the superiority of policies such as in-work benefits, or tax-credit on low earnings. Analogous policies have been in part implemented or considered as alternatives or complements to mean-tested transfers in various countries during the last decades. ${ }^{6}$ Although nothing prevents the design of mechanisms that combine transfers and subsidies, the theoretical nature of the optimal taxation literature (even in its empirical applications) in practice has forced the analysis to address transfer-based and subsidy-based mechanisms as if they were strictly alternative. In what follows we consider transfer-based, subsidy-based and mixed policies.

\subsection{Unconditional vs. Conditional Policies}

The theoretical contributions are not conclusive on this issue: for example, Besley (1990) concludes for the superiority of means-testing, while Sadka et al. (1982) favour unconditional policies. The transfers mentioned in Sect. 2.2, when actually implemented, are typically conditional. However, the alternative of unconditional transfers deserves consideration at least because by construction it avoids poverty traps and entails low administrative costs. Poverty traps are avoided since the benefit received does not depend on the recipient's own income. According to U.S. estimates, the

\footnotetext{
5 Among others: Spence (2011), Standing (2012), Sachs and Kotlikoff (2012), Krugman (2013), Hughes (2014), Marchant et al. (2014) and Brynjolfsson and McAfee (2014).

6 Recent empirical analysis of the effects of policies such as in-work benefits or tax credits include, among others, Fang and Keane (2004) for the US, Francesconi et al. (2009) for the UK and Aaberge and Flood (2008) for Sweden.
} 
administrative cost of a non-means-tested transfer such as an unconditional basic income is around 1-2\%, while means-testing boosts the cost to four or five times that amount (Van de Walle 1999). Means-testing introduces obvious incentives for income underreporting and erroneous reporting, such as incorrect inclusions and exclusions. For example, the rate of overpayment due to fraud and error in the United Kingdom in 2010 is estimated at around $1 \%$ for non-means-tested benefits and around $4 \%$ for means-tested ones. The costs (monetary and other) to recipients of means-tested transfers are substantial, as can be inferred from take-up rates well below $100 \%$ for most means-tested benefits (Atkinson 2011). Critical analyses of these policies point out that program designs with more sophisticated incentives and eligibility conditions do not completely overcome the deficiencies of means-tested and conditional policies while introducing new problems (Bryan 2005; Handler and Babcock 2006). Incentiveaugmented conditional minimum income policies do not eliminate the poverty-trap problems. Moreover, they do not eliminate other problems, including take-up costs, stigma, and paternalism, that lead to low take-up rates (Atkinson 2011) and marginalization. Programs focusing on wage subsidies or tax credits for low-income earners introduce additional distortions by favoring sectors that employ low-wage workers (Standing 2011). Moreover, recent ex-post reform evaluations (Barrientos and LloydSherlock 2002) and experimental evidence (e.g. Standing 2008; Akee et al. 2010; Blattman et al. 2013) suggest that unconditional transfers might promote more efficient choices in education, production and occupational career. The issue of unconditionally is intertwined with the issue of universality-illustrated in Sect. 2.1. According to many authors, an unconditional basic income policy promises to provide an efficient, flexible, and automatic mechanism for protecting against shocks and for redistributing the benefits of automation and globalization (e.g. Standing 2012; Krugman 2013; Hughes 2014). Moreover, it would provide an efficient mechanism for helping the reallocation of jobs and resources in the globalized economy, where employers need flexibility to compete on a global scale and employees need support to redesign their careers and occupational choices. Studies have found that a considerable number of recipients of unconditional cash transfers use the money to pay for training in new skills and to cover related costs of changing jobs (e.g. Blattman et al. 2013). The idea of paying everyone an unconditional amount of money goes back to Thomas Paine's pamphlet Agrarian Justice, ${ }^{7}$ which called for compensating the original "owners" of the commons (by definition, everyone), which had been expropriated when land holding became private. More generally, the returns from an efficiently exploited common resource should be (to some extent) distributed among the resource's original owners. The benefits of automation and globalization are similar to the returns from an efficiently exploited natural resource in that they introduce more efficient ways of producing and exchanging goods at the cost of "expropriating" the jobs and skills of the original stakeholders. A similar approach, also traceable back to Paine, is adopted by Meade (1993). A common criticism against unconditional basic income argues that it is unfair since it pays the benefits to everyone, not only to the "deserving" ones. However, the argument is more illusory than real. Beyond a certain level of gross

7 Agraria Justice, originally published in 1797, is available at http://en.wikisource.org/wiki/ Agrarian_Justice. 
income, the unconditional benefit is completely exhausted and "given back" through taxes. The break-even point depends on how progressive the tax system is. If $B$ is the unconditional benefit and $T(I)$ is the tax to be paid at (own) gross income $I$, the break-even level of gross income is $T^{-1}(B)$. For example, with a flat tax rate $t$ and an unconditional benefit $B$, the break-even level of gross income would be equal to $B / t$. From the household's point of view, the system is equivalent to a negative income tax with a benefit-reduction rate equal to the tax rate $t$. Different degrees of redistribution can be achieved with an appropriate combination of the unconditional benefit $B$ and of the tax rule $T$ (). Of course, an unconditional benefit is more costly than an unconditional one. In practice, taxes on high income will have to be heavier. Therefore, the real issues to be faced when evaluating unconditional policies (as compared to conditional ones) are the (possible) disincentive effect on high-income individuals' supply and the (possible) positive incentive effect—due to the absence of poverty traps-on low-income individuals' supply.

The general issues mentioned above strongly motivate the interest in analysing the alternative: conditional vs. unconditional policies. However, given the model and the data used, our study will only be able to throw light on the issues of the relative redistributive performance, the poverty trap effect and the incentives to labour supply.

\subsection{Amount of the Basic Income}

Some advocates of basic income policies have proposed transfers or subsidies that replace all or most other welfare policies (not only income support policies). However, the typical level of a basic income (in proposed or implemented reforms) — through either as a transfer or a subsidy - is not larger than the poverty level and in most cases is much lower, mainly because the mechanisms are usually designed as complementary with respect to other welfare and social policies. In this paper, we investigate the performance of transfers or subsidies of different amounts up to the poverty level.

\subsection{Progressive Taxes vs. Flat Tax}

Basic income policies have been frequently proposed together with the flat tax (e.g. Atkinson 1995). The transfer makes the system progressive anyway, even when coupled with a flat tax rate (which is attractive on its own for its simplicity and transparency). A different motivation for the flat tax is that it promises to counterbalance the costs and/or the (supposedly) negative incentives coming from income support with better incentive to labour supply for the (supposedly) most productive fraction of the population. These last motivations must be checked against many arguments in favour of progressive marginal rates (e.g. Diamond and Saez 2011), in particular, among them, the empirical evidence upon the intensive and extensive labour supply elasticities (e.g. Aaberge et al. 1999, 2004; Aaberge and Colombino 2013; Meghir and Phillips 2008). In our simulation exercise both flat-tax and progressive-tax versions of the alternative income support mechanisms are analysed. 


\section{The Reforms}

We simulate and evaluate alternative hypothetical reforms that replace the actual taxbenefit system. They are stylized cases representative of the different policies that are discussed or even actually implemented in many countries. Each reform, when simulated, completely substitutes the current (1998) tax-benefit system.

We chose to consider a large set of general reform designs since we think this approach is more appropriate for the current status of the debate in Italy, which is more explorative rather than focussed on a specific policy. The "Appendix" provides a more detailed description of the reforms by specifying net available income as a function of taxable income.

A key parameter in the definition of the policies is the threshold $G$ defined as follows. Let:

$x_{i}=$ total net available income (current) of household $i$ (including both couples and singles),

$N_{i}=$ total number of components of household i.

Define the "individual-equivalent" income $\tilde{x}_{i}=x_{i} / \sqrt{N_{i}}$ and the Poverty Line $P=\operatorname{median}(\tilde{x}) / 2{ }^{8}$ Then $G_{i}=a P \sqrt{N_{i}}$, where $a$ is a policy parameter. $G_{i}$ is a proportion $a$ (a policy parameter) of the (adjusted for household's size) poverty level. The "square root scale" is one of the equivalence scales commonly used in OECD publications. For each reform, we simulate three versions with different values of $a: 1,0.75$ and 0.50 . For example, $G=0.5 P \sqrt{3}$ means that for a household with 3 components the threshold $G$ is $1 / 2$ of the Poverty Line times the equivalence scale $\sqrt{3}$.

\subsection{Conditional Basic Income (CBI)}

Each individual receives a transfer equal to $G-I$ if single or $G / 2-I$ if partner in a couple provided $I<G$ (or $I<G / 2$ ), where $I$ denotes individual taxable income. This is the standard conditional (or means-tested) income support mechanism, with a $100 \%$ marginal benefit reduction rate. Friedman (1962) and Tobin (1996) proposed milder versions - usually denoted as negative income tax — with lower benefit reduction rates in order to improve the incentives to labour supply.

\subsection{Unconditional Basic Income (UBI)}

Each individual receives an unconditional transfer equal to $G$ if single or $G / 2$ if partner in a couple. It is the basic version of the system discussed for example by Van Parijs (1995) and also known in the policy debate as "citizen income" or "social dividend"

\footnotetext{
8 The definition of the poverty line as half the median of the (equivalent) income is one of the many commonly used definitions in the literature and in official statistical reports. Typically, either the mean or the median are used, with a proportion around 50 or $60 \%$. There are no strong theoretical reasons for using one or the other definition, besides the standard argument that the median is a robust statistic and half-the-median corresponds to the somewhat intuitive 25th percentile of the distribution. In the empirical exercise presented in this paper, the definition of a poverty line is purely instrumental to the computation of benefits to be received under the alternative reforms.
} 
(Meade 1993; Van Trier 1995). It is also close to the "participation income" discussed by Atkinson $(1995,2011,2015)$. Under a flat tax regime, it would be equivalent to special case of the Negative Income Tax (Friedman 1962; Tobin 1996) with a benefitreduction rate equal to the flat tax rate. It is implemented - in a rather limited form - in Alaska. The Brazilian Government announced the intention of progressively extend the Bolsa Familia to an unconditional universal basic income. It is object of local experiments in India and Africa (Pasma 2014) and in the Western world (e.g. Akee et al. 2010).

\subsection{Wage Subsidy (WS)}

Each individual receives a $10 \%$ subsidy on the gross hourly wage and her/his income is not taxed as long as her/his gross income (including the subsidy) does not exceed $G$ if single or $G / 2$ if partner in a couple. In essence, this is close to various in-work benefits or tax-credits reforms introduced in the USA (e.g. Fang and Keane 2004), in the UK (e.g. Francesconi et al. 2009) and recently also in Sweden (e.g. Aaberge and Flood 2008). Figari (2011), Colonna and Marcassa (2012) and De Luca et al. (2012) simulate the performance of hypothetical reforms of the in-work benefit or tax-credit type in Italy.

$\mathrm{CBI}+\mathrm{WS}$ and $\mathrm{UBI}+\mathrm{WS}$ are mixed mechanisms where the transfer is complemented by the wage subsidy: in these cases the threshold $G$ is reset as $0.5 G .^{9}$

For each of the above five types we distinguish two versions: a flat tax version, in which the tax rule applied to incomes above $G$ for singles or $G / 2$ for the partners of couple is a fixed proportion $t$; a progressive tax version, in which the tax rule is progressive and replicates the current system with marginal tax rates proportionally adjusted according to a constant $\tau$. The parameters $t$ and $\tau$ are endogenously determined within the reform simulation so that the total net tax revenue is equal to the one collected under the current tax-benefit system. The marginal tax rates as applied in the current (1998) system are reported in the "Appendix". Altogether we have 5 (types) $\times 3($ values of $a) \times 2$ (tax rules) $=30$ alternative reforms.

\subsection{Current (1998) Policy (CURRENT)}

The current income support system is not amenable to a synoptic comparison to the reforms: the latter are stylized and universal, the former is fragmented and categorical. ${ }^{10}$ The two parameters along which it can be compared to the reforms (Table 4) are the tax rule (progressive) and the average expected annual benefit of $€ 1212$, which implies an average coverage equal to 0.10 . The policies we can take account of are those measured in the EUROMOD dataset based on SHIW1998. We do not need to

\footnotetext{
9 A mixed system close to CBI + WS was proposed for Italy by De Vincenti and Paladini (2009).

10 See Negri and Saraceno (1996) and Onofri (1997) for a description of the system (not radically different from the present one) implemented at the end of the 90 s in Italy.
} 
simulate the 1998 system. Its result is just what we observe in the sample. When simulating the reforms, all the policies of the 1998 system are cancelled.

\section{The Microeconometric Model}

\subsection{Household Behaviour}

A key element of our exercise consists of accounting for behavioural responses to the new opportunity sets determined by the reforms. To this end, we use a microeconometric model of household labour supply. The basic modelling framework belongs to the Random Utility family. We will consider households with two decision-makers (couples) or one decision-maker (singles). In both cases, the decision-makers are aged 20-55 and are not retired nor students. Of course there might be other people in the household, but their behaviour is taken as exogenous. We adopt a "unitary" representation of the household decision process. ${ }^{11}$ Couple $n$ is assumed to solve the following problem

$$
\begin{aligned}
& \max _{h_{F}, h_{M}, j} U^{n}\left(C, h_{F}, h_{M}, j\right) \\
& \text { s.t. } \\
& \left(h_{F}, h_{M}, j\right) \in \Omega \\
& C=R\left(w_{F}^{n} h_{F}, w_{M}^{n} h_{M}, y^{n}\right)
\end{aligned}
$$

where $U^{n}\left(C, h_{F}, h_{M}, j\right)$ is the utility function; $h_{g}$ is the average weekly hours of work required by the chosen job in the choice set for partner of gender $g=\mathrm{F}$ (female) or $\mathrm{M}$ (male); $w_{g}^{n}$ is the hourly wage rate of partner $g ; y^{n}$ is the vector of exogenous household gross incomes; $C$ is the net disposable household income; $j$ is the unobserved (by the analyst) characteristics of the household-job match; $\Omega$ is the opportunity set containing jobs $\left(h_{F}, h_{M}, j\right)$, including those with $h_{F}=0$ and/or $h_{M}=0$ (i.e. non-participation); $R$ is the tax-transfer rule that transforms gross incomes into net available household income.

We write the utility function $U^{n}\left(C, h_{F}, h_{M}, \varepsilon\right)$ as the sum of a parametric systematic part and a random component:

$$
\mathrm{U}^{n}\left(C, h_{F}, h_{M}, j\right)=V\left(R\left(w_{F}^{n} h_{F}, w_{M}^{n} h_{M}, y^{n}\right), h_{F}, h_{M}, Z^{n} ; \theta\right)+\varepsilon(j)
$$

where $Z^{n}$ is a vector of household characteristics, $\theta$ is a vector of parameters to be estimated and the random variable $\varepsilon$ accounts for characteristics of the job-household match that are observed by the household but not by the researcher (McFadden 1974).

We denote with $p\left(h_{F}, h_{M}\right)$ the relative frequency (or probability density function) of jobs of type $\left(h_{F}, h_{M}\right) \in \Omega$. The random variable $\varepsilon$ is assumed to be i.i.d. Type I Extreme Value. By specifying $p\left(h_{F}, h_{M}\right)$ as "uniform with peaks", it turns out that we

\footnotetext{
11 We did not adopt the alternative "collective" approach (e.g. Vermeulen 2006) because of its severe identification requirements (at least with our available data). Moreover, the typical empirical strategy adopted with the collective approach (the so-called decentralized-sharing rule specification) raises some doubts about its applicability to tax reform evaluation problems, since it requires convex opportunity sets and it does not provide a structural representation of the household decision process.
} 
can write the probability that household $n$ subject to tax-transfer regime $R$ chooses $h_{F}=f, h_{M}=m$ as follows ${ }^{12}$ :

$$
\begin{aligned}
& P^{n}(f, m ; \theta, R) \\
& =\frac{\exp \left\{V\left(R\left(w_{F}^{n} f, w_{M}^{n} m, y^{n}\right), f, m, Z^{n} ; \theta\right)+\sum_{k=1}^{4} \gamma_{F k} D_{F k}(f)+\sum_{k=1}^{4} \gamma_{M k} D_{M k}(m)\right\}}{\sum_{\left(h_{F}, h_{M}\right)} \exp \left\{V\left(R\left(w_{F}^{n} h_{F}, w_{M}^{n} h_{M}, y^{n}\right), h_{F}, h_{M}, Z^{n} ; \theta\right)+\sum_{k=1}^{4} \gamma_{F k} D_{F k}\left(h_{F}\right)+\sum_{k=1}^{4} \gamma_{M k} D_{M k}\left(h_{M}\right)\right\}}
\end{aligned}
$$

where

$$
\begin{aligned}
& D_{g 1}\left(h_{g}\right)= \begin{cases}1 & \text { if } 17 \leq h_{g} \leq 32 \\
0 & \text { otherwise }\end{cases} \\
& D_{g_{2}}\left(h_{g}\right)= \begin{cases}1 & \text { if } 33 \leq h_{g} \leq 48 \\
0 & \text { otherwise }\end{cases} \\
& D_{g 3}\left(h_{g}\right)= \begin{cases}1 & \text { if } 49 \leq h_{g} \\
0 & \text { otherwise }\end{cases} \\
& D_{g 4}\left(h_{g}\right)= \begin{cases}1 & \text { if } 0<h_{g} \\
0 & \text { otherwise }\end{cases} \\
& \text { with g }=\mathrm{F} \text { (female) or M (male). }
\end{aligned}
$$

In a similar way, a single $s$ of gender $g$ is assumed to solve a constrained utility maximization problem as follows:

$$
\begin{aligned}
& \max _{h, j} U_{g}^{s}(C, h, j) \\
& \text { s.t. } \\
& (h, j) \in \Omega_{g} \\
& C=R\left(w^{s} h, y^{s}\right)
\end{aligned}
$$

where $h$ is the average weekly hours of work required by the chosen job.

In this case, the utility function $U_{g}^{s}(C, h, j)$ will be written as follows:

$$
U_{g}^{s}(C, h ; j)=V\left(R\left(w^{s} h, y^{s}\right), h, Z^{s} ; \theta_{g}\right)+\varepsilon(j)
$$

Proceeding as we did with couples we end up with:

$$
P^{s}\left(g ; \theta_{g}, \gamma_{g}, R\right)=\frac{\exp \left\{V\left(R\left(w_{g}^{s} g, y^{s}\right), g, Z^{s} ; \theta\right)+\sum_{k=1}^{4} \gamma_{g k} D_{g k}(g)\right\}}{\sum_{h} \exp \left\{V\left(R\left(w_{g}^{s} h, y^{s}\right), h, Z^{s} ; \theta\right)+\sum_{k=1}^{4} \gamma_{g k} D_{g k}(h)\right\}}
$$

Under appropriate assumptions (e.g. Aaberge and Colombino 2013), the coefficients of the dummies can be given the following interpretation, which turns out to be useful for the development of the equilibrium simulation procedure (Colombino 2013):

$$
\begin{aligned}
& e^{\gamma_{g 4}} \propto J_{g}, \\
& e^{\gamma_{g k}} \propto J_{g k} / J_{g}, \quad k=1,2,3 .
\end{aligned}
$$

\footnotetext{
12 See for example Aaberge et al. (1995, 1999), Dagsvik (2000a), Dagsvik and Strøm (2006) and Colombino et al. (2010).
} 
where $J_{g}$ is the number of market jobs available in gender g's opportunity set and $J_{g k}$ is the number of market jobs with hours h such that $D_{g k}(h)=1 .{ }^{13}$ When computing (3) and (7), the set of hours values is approximated by a discrete set containing the value 0 plus ten values randomly chosen from the ten intervals of weekly hours 1-8, 9-16, 17-24, 25-32, 33-40, 41-48, 49-56, 57-64, 65-72, 73-80. Therefore the singles' and the couples' opportunity sets contain respectively 11 and 121 alternatives. ${ }^{14}$ In order to compute net household income $C$ for each alternative under the current tax-benefit regime, we use the EUROMOD Microsimulation model. ${ }^{15}$ First, EUROMOD is used to generate the gross incomes since the Italian data are originally collected as net incomes. Gross wage rates are computed by dividing gross earning by hours of work. Given the gross wage rates, we compute gross earnings and incomes at each point in the choice set. Finally, EUROMOD is used again to compute net income $\mathrm{C}$ at each point in the choice set under the current tax-benefit regime. Wage rates are assumed to be independent of hours of work required on the various jobs available in the choice set. $^{16}$

For the observations with missing data on earnings and/or hours of work, gross wage rates are imputed on the basis of a wage equation estimated on the subsample with data on earnings and hours and corrected for sample selection. The procedure for selection-correction follows Dagsvik (2000b) and is compatible with assuming the same process for the selection of the subsample and the labour supply decision, although it does not a priori constrain the two processes to be identical. ${ }^{17}$ The random component of the wage equation is taken into account when computing $\mathrm{C}$ and other quantities involving the wage rate and is integrated-out with a simulation procedure.

\footnotetext{
13 Expressions (3) and (7) are close to other multinominal logit models "augmented" by alternative-specific dummies (e.g. Van Soest 1995; Kornstad and Thoresen 2007). Here however we adopt a specific structural interpretation of the dummies' coefficients according to expression (8).

14 A comparison and evaluation of different procedures to specify the choice set is provided by Aaberge et al. (2009).

15 EUROMOD is a tax-benefit microsimulation model for the European Union that enables researchers and policy analysts to calculate, in a comparable manner, the effects of taxes and benefits on household incomes and work incentives for the population of each country and for the EU as a whole. EUROMOD was originally designed by a research team under the direction of Holly Sutherland at the Department of Economics in Cambridge, UK. It is now developed and updated at the Microsimulation Unit at ISER, Essex, UK.

16 Since also the self-employed are included in the sample, it might be important to drop the independence assumption. We tried to estimate different wage rate functions for different hour intervals but we did not obtain satisfactory results. We can add that we also estimated the model and run some simulations on the wage-employed subsample and we did not obtain important differences.

17 The estimates of the wage equation are not reported here and are available upon request from the author. It is possible to adopt a simultaneous method of estimation even without restricting the two processes to be identical. However we do not think that a simultaneous method is obviously superior, although in principle it is more efficient than two-step procedures. While the likelihood of the Conditional Logit model has nice properties and ensures an easy convergence of the estimates, the same is not necessarily true of a likelihood that incorporates a wage function to be estimated. Our personal experience with both simultaneous and two-step procedures in practice speaks in favour of the latter as more flexible and robust.
} 


\subsection{Empirical Specification of Preferences}

We choose a quadratic specification since it represents a good compromise between flexibility and ease of estimation:

$$
\begin{aligned}
V^{n}= & \theta_{C} C+\theta_{F}\left(T-h_{F}\right)+\theta_{M}\left(T-h_{M}\right)+\theta_{C C} C^{2}+\theta_{F F}\left(T-h_{F}\right)^{2}+\theta_{M M}\left(T-h_{M}\right)^{2} \\
& +\theta_{C F} C\left(T-h_{M}\right)+\theta_{C M} C\left(T-h_{M}\right)+\theta_{F M}\left(T-h_{F}\right)\left(T-h_{M}\right) \\
V^{s}= & \theta_{C} C+\theta_{g}\left(T-h_{g}\right)+\theta_{C C} C^{2}+\theta_{g g}\left(T-h_{g}\right)^{2}+\theta_{C g} C\left(T-h_{g}\right)
\end{aligned}
$$

where $V^{n}$ and $V^{s}$ denote the systematic part of the utility function respectively for couples and singles and $T$ denotes total available time. Some of the above parameters $\theta s$ are made dependent on characteristics:

$$
\begin{aligned}
\theta_{F}= & \beta_{F 0}+\beta_{F 1}(\text { Age of the wife })+\beta_{F 2}(\text { Age of the wife })^{2} \\
& +\beta_{F 3}(\# \text { Children })+\beta_{F 4}(\# \text { Children under } 6)+\beta_{F 5}(\# C h i l d r e n ~ 6-10) \\
\theta_{M}= & \beta_{M 0}+\beta_{M 1}(\text { Age of the husband })+\beta_{M 2}(\text { Age of the husband })^{2} \\
& +\beta_{M 3}(\# \text { Children })+\beta_{M 4}(\# \text { Children under } 6)+\beta_{M 5}(\# \text { Children } 6-10) \\
\theta_{g}= & \beta_{g 0}+\beta_{g 1}(\text { Age })+\beta_{g 2}(\text { Age })^{2} \\
& +\beta_{g 3}(\# \text { Children })+\beta_{g 4}(\# \text { Children under } 6)+\beta_{g 5}(\# \text { Children } 6-10) \\
\theta_{C}= & \left.\beta_{C 0}+\beta_{C 1} \text { (Household's size }\right) .
\end{aligned}
$$

Notice that the parameters are estimated separately for couples, single females and single males.

\subsection{Data and Estimates}

For the estimation and simulation exercise, we use a EUROMOD dataset based on the Survey of Household Income and Wealth (SHIW1998). ${ }^{18}$

The inclusion criteria are as follows:

- Couple and single households;

- Employed (self-employed included), unemployed or inactive (students and disabled are excluded);

- Both partners of couple households and heads of single households aged 20-55.

The Maximum Likelihood estimates based on the sample of couples, single men and single women (respectively 2955, 291 and 366 observations) are reported in Table 1.

\footnotetext{
18 We use a microeconometric model developed at an early stage of the project. More recent datasets are of course available. However, there is no evidence of significant changes in households' preferences. Moreover, since 1998 the basic structure of the tax-transfer system has remained essentially the same, a part from some adjustments in marginal tax rates, deductions and unemployment benefits. These changes, as well as those in the socio-demographic composition of the population are in any case minor when compared to the changes implied by the reforms.
} 


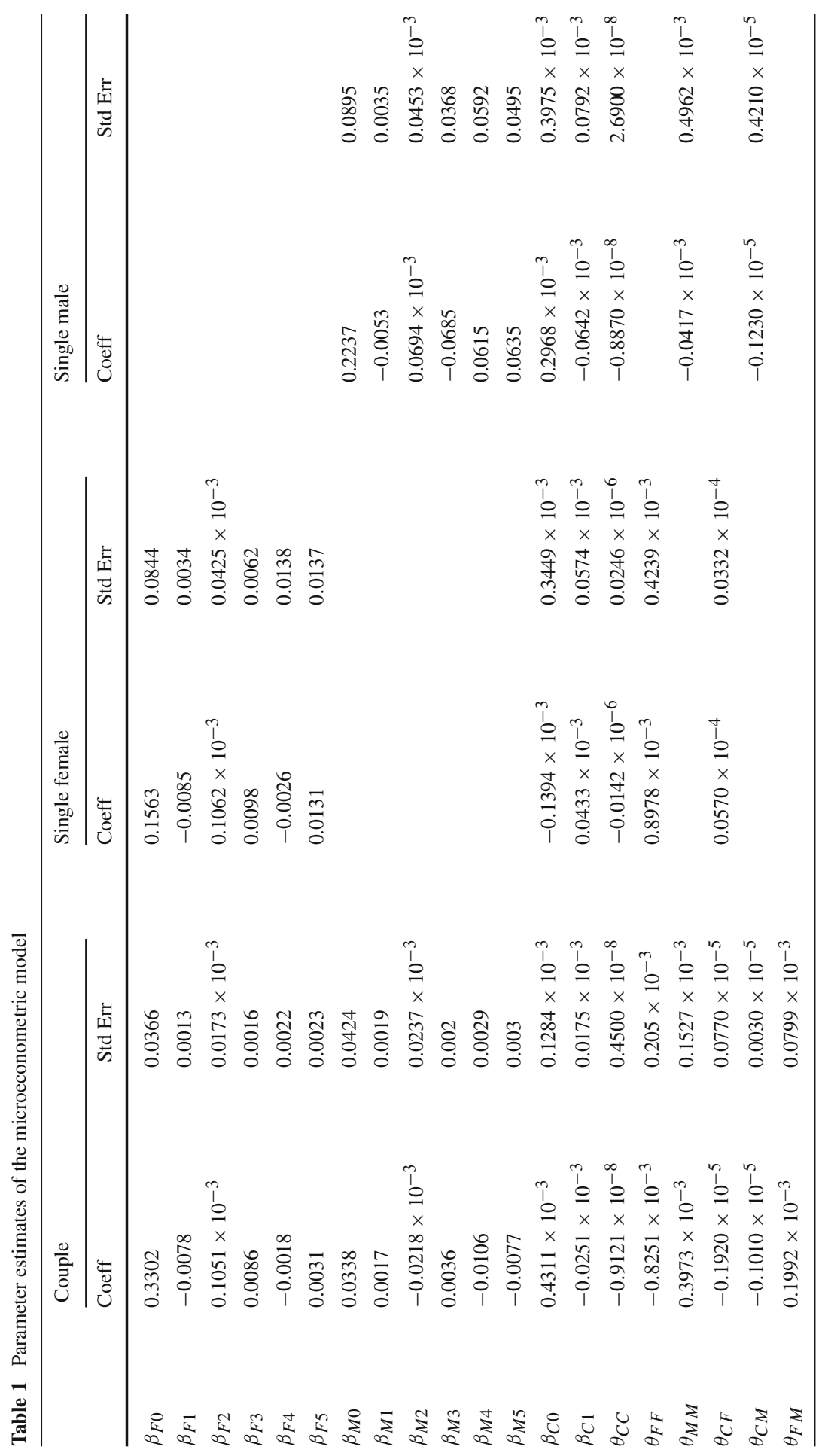




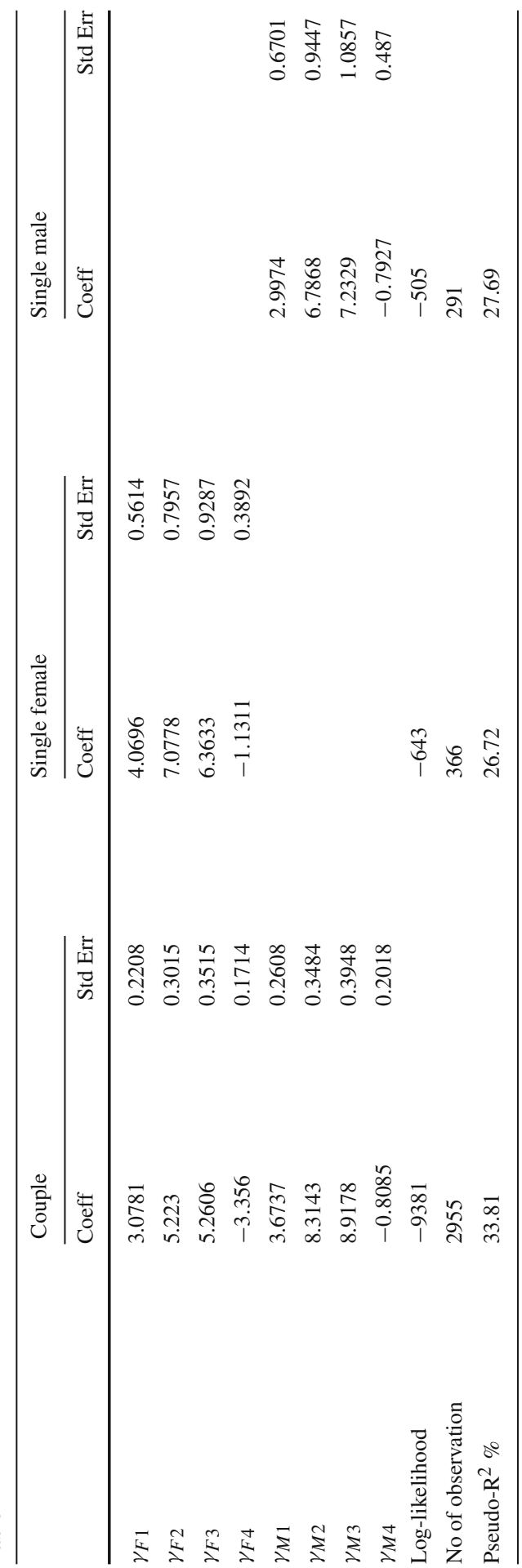


Table 2 Observed and simulated labour supply choices

\begin{tabular}{|c|c|c|c|c|c|c|c|c|}
\hline \multirow[t]{3}{*}{ Weekly hours } & \multicolumn{4}{|l|}{ Female } & \multicolumn{4}{|l|}{ Male } \\
\hline & \multicolumn{2}{|l|}{ Single } & \multicolumn{2}{|l|}{ Married } & \multicolumn{2}{|l|}{ Single } & \multicolumn{2}{|l|}{ Married } \\
\hline & Observed & Simulated & Observed & Simulated & Observed & Simulated & Observed & Simulated \\
\hline 0 & 0.169 & 0.169 & 0.477 & 0.477 & 0.086 & 0.086 & 0.049 & 0.049 \\
\hline $1-8$ & 0.008 & 0.025 & 0.006 & 0.013 & 0.017 & 0.023 & 0.004 & 0.010 \\
\hline $9-16$ & 0.025 & 0.007 & 0.016 & 0.008 & 0.014 & 0.009 & 0.010 & 0.003 \\
\hline $17-24$ & 0.109 & 0.140 & 0.089 & 0.100 & 0.048 & 0.067 & 0.030 & 0.040 \\
\hline $25-32$ & 0.079 & 0.049 & 0.063 & 0.052 & 0.045 & 0.026 & 0.022 & 0.013 \\
\hline $33-40$ & 0.462 & 0.376 & 0.261 & 0.207 & 0.502 & 0.447 & 0.521 & 0.481 \\
\hline $41-48$ & 0.074 & 0.159 & 0.034 & 0.088 & 0.117 & 0.172 & 0.141 & 0.181 \\
\hline $49-56$ & 0.014 & 0.037 & 0.027 & 0.036 & 0.093 & 0.106 & 0.121 & 0.132 \\
\hline $57-64$ & 0.036 & 0.019 & 0.014 & 0.013 & 0.048 & 0.042 & 0.060 & 0.055 \\
\hline $65-72$ & 0.014 & 0.011 & 0.008 & 0.004 & 0.017 & 0.017 & 0.027 & 0.025 \\
\hline $73-80$ & 0.010 & 0.008 & 0.005 & 0.002 & 0.013 & 0.005 & 0.015 & 0.011 \\
\hline
\end{tabular}

Proportion of households in each weekly hours bracket

Table 3 Regularity of the utility function (systematic part)

\begin{tabular}{|c|c|c|c|c|c|c|}
\hline & \multicolumn{2}{|c|}{$\begin{array}{l}\text { Percentage of observations } \\
\text { with utility increasing } \\
\text { w.r.t. leisure }\end{array}$} & \multicolumn{2}{|c|}{$\begin{array}{l}\text { Percentage of observations } \\
\text { with utility increasing } \\
\text { w.r.t. income }\end{array}$} & \multicolumn{2}{|c|}{$\begin{array}{l}\text { Percentage of observations } \\
\text { with utility increasing w.r.t. } \\
\text { income and quasi-concave }\end{array}$} \\
\hline & $\begin{array}{l}\text { At the chosen } \\
\text { alternative }\end{array}$ & $\begin{array}{l}\text { At all } \\
\text { alternatives in } \\
\text { the choice set }\end{array}$ & $\begin{array}{l}\text { At the chosen } \\
\text { alternative }\end{array}$ & $\begin{array}{l}\text { At all } \\
\text { alternatives in } \\
\text { the choice set }\end{array}$ & $\begin{array}{l}\text { At the chosen } \\
\text { alternative }\end{array}$ & $\begin{array}{l}\text { At all } \\
\text { alternatives in } \\
\text { the choice set }\end{array}$ \\
\hline Singles & 100.0 & 100.0 & 94.0 & 91.0 & 90.9 & 88.3 \\
\hline Couples & 100.0 & 100.0 & 96.6 & 96.4 & 94.3 & 91.6 \\
\hline
\end{tabular}

Table 2 documents the model's fitting performance by comparing the observed and the simulated choices of alternative ranges of weekly hours of work. The ability to replicate the observed choice appears to be pretty good, somewhat less satisfactory for singles.

Most of the observations at most of the points in the choice set satisfy the regularity conditions for the utility function (systematic part). In Table 3 we show, for couples and singles, the percentage of observations with utility function increasing in income, increasing in leisure and quasi-concave, when computed at the chosen alternative or at all the alternatives in the choice set. Most of the violations are concentrated on alternatives that are chosen by a small number of households. The regularity statistics at all alternatives in the choice set are particularly important in view of policy simulation and represent a much more severe test than the regularity statistics at the chosen alternative: yet the results turn out to be rather close for the two types of statistics. 


\section{Policy Simulation and Evaluation}

\subsection{Simulating Behavioural Responses}

The estimated model simulates the effects of alternative hypothetical tax-transfer reforms upon variables such as hours worked, earnings, taxes paid, benefits received etc. There are many possible methods that can be used to compute these predictions. We adopt the method of computing the expected value of the variables of interest. Let $P^{n}(f, m ; \theta, \gamma, R)$ be the probability that household $n$ chooses $(f, m)$ under the $R$ tax-transfer regime, computed on the basis of the estimated parameters. Suppose we are interested in simulating the expected value of some function $\psi^{n}(f, m)$ of the choices made. Then we compute the expected value of that variable after the policy is implemented as follows:

$$
E\left(\psi^{n}(f, m)\right)=\sum_{(f, m) \in \Omega} \psi^{n}(f, m) P_{n}\left(f, m, Z^{n} ; \theta, \gamma, R\right)
$$

An analogous procedure is used for singles.

\subsection{Fiscal Sustainability and Market Adjustments}

The simulation has two distinctive features that are not common in the tax reform literature.

First, the reforms are simulated under the constraint of being fiscally neutral, i.e. they generate the same total net tax revenue as the 1998 system. The calibration parameters are a constant tax rate $t$ in the flat tax systems and a proportional change $\tau$ of the current marginal tax rates in the progressive tax systems.

Second, the simulation is conducted under equilibrium conditions. We adopt a procedure - fully explained in Colombino (2013) — that is specifically appropriate for the microeconometric model. The model adopts a refinement consisting of introducing alternative-specific constants, which should account for a number of factors such as the different density or accessibility of different types of jobs, search or fixed costs and systematic utility components otherwise not accounted for. ${ }^{19}$ However, the authors adopting the "dummies refinement" so far have performed the simulations while leaving the dummies' coefficients $\gamma$ 's unchanged when computing the new choice probabilities according to expressions (3) and (7). The policy simulation is most commonly interpreted as a comparative statics exercise, where different equilibriainduced by different tax-benefit regimes-are compared. We claim that the standard procedure in general is not consistent with the comparative statics interpretation. Comparative statics is meant to compare different equilibria. Since the $\gamma$ 's reflect—at least in part — the number and the composition of available jobs (see expression (8)) and since the number of people willing to work and their distribution across different job

19 See for example Van Soest (1995), Aaberge et al. (1995, 1999, 2000, 2004), Aaberge and Colombino (2013), Kalb (2000), Dagsvik and Strøm (2006), Kornstad and Thoresen (2007) and Colombino (2013). 
types in general change as a consequence of the reforms, it follows that in general the $\gamma$ 's must also change, at least if we adopt a basic notion of equilibrium requiring that the number of people willing to work must equal to the number of available jobs. In this exercise we assume that the number of available jobs depends on the average wage rate according to a constant labour demand elasticity (here set equal to -1 ). ${ }^{20}$ Changes in the wage rates induce changes in the number of available jobs, in the coefficients $\gamma$ 's (according to expression (8)) and in the choice probabilities, and therefore in the expected number of people choosing to work. In the course of the simulation the wage rate distributions and the coefficients $\gamma$ 's are iteratively adjusted so that the number of available jobs is equal to the expected number of people choosing to work.

For each reform, the simulation requires a two-level procedure. At the "low" level, household choices are simulated given the wage rates, the $\gamma$ 's and the reform's parameters. At the "high" level, the wage rates, the $\gamma$ 's and the tax-benefit parameters are iteratively adjusted so that the social welfare function (see Sect. 5.3) is maximized (conditional on the given reform) subject to the constraints that total net tax revenue remains constant and the equilibrium conditions are satisfied. As a consequence, the fiscally neutral equilibrium allocation reached under the different social welfare criteria is in general different. ${ }^{21}$

Summing up, even though we do not provide a general equilibrium or macroeconomic evaluations of the reforms, we are able to account for fiscal sustainability and wage rate-labour demand adjustments, thus allowing a comparison of policies that is fully consistent with the comparative-statics principles.

\subsection{Social Evaluation}

Besides providing results on behavioural responses (labour supply, incomes etc.), we focus on the computation of (various versions of) a social welfare index. For three main reasons, we rely on it as the main criterion for comparing alternative reforms. First, the social welfare index is a natural product of the same theory on which the microeconomic model is based. Second, the social welfare index is a comprehensive scalar measure that permits a complete ordering of the reforms. Third, the social welfare index provides a larger and more appropriate perspective than the one provided by behavioural or fiscal responses only. Especially when analysing income support policies, two issues of great concern are the possible negative effects on labour supply and on the tax burden. It must be remembered that our simulations preserve fiscal neutrality and that all the effects on labour supply and the implications for taxes and incomes are endogenously taken into account. That said, labour supply is obviously important but an exclusive focus on it can happen to be misleading. For example, as we have seen in the Introduction, one of the motivation for designing universal income support poli-

20 Most of the empirical estimates of the long run labour demand elasticity belong to a range of values close to -1 or -0.5 . Colombino (2013) compares the simulation results for various different values of the labour demand elasticity.

21 For the simulation of the reforms we did not use the EUROMOD algorithm. We run our microeconometric model, which requires specific programming. At different stages of the project, we used Amoeba (a STATA module dedicated to non-standard optimization problems), Gauss and R. 
cies is the need to redistribute the gains from globalization and technological progress (automation). The gains, when sufficiently redistributed, would entail an income effect. A reduction of labour supply might then be a natural implication and should not be considered-by itself - negative. The social welfare index accounts both for the value of leisure time for every household and for the social value of redistribution across households. As to the tax burden, clearly there are implications that are not included by social welfare indexes and yet might be relevant from the point-of-view of the policy makers. For example, the top marginal tax rate might be a matter of concern for its implications on political consensus. In any case, besides the evaluations based on social welfare indexes, in Table 6 we also report results on behavioural, fiscal and preferences (number of "winners") that in principle permit alternative rankings of the reforms.

We define four alternative social welfare indexes. They require the following steps.

1. Compute the expected maximum utility attained by household $n$ under tax-transfer regime $R^{22}$ :

$$
\begin{aligned}
& V^{n}(R) \\
& =\left\{\begin{array}{l}
\ln \left(\sum _ { ( h _ { F } , h _ { M } ) } \operatorname { e x p } \left\{V\left(R\left(w_{F}^{n} h_{F}, w_{M}^{n} h_{M}, y^{n}\right), h_{F}, h_{M}, Z^{n} ; \theta, \gamma\right)\right.\right. \\
\left.\left.\quad+\sum_{k=1}^{4} \gamma_{F k} D_{F k}\left(h_{F}\right)+\sum_{k=1}^{4} \gamma_{F k} D_{M k}\left(h_{M}\right)\right\}\right) \\
\text { if couple } \\
\ln \left(\sum_{h} \exp \left\{V\left(R\left(w^{n} h, y^{n}\right), h, Z^{n} ; \theta, \gamma\right)+\sum_{k=1}^{4} \gamma_{k} D_{k}(h)+\sum_{k=1}^{4} \gamma_{k} D_{k}(h)\right\}\right) \\
\text { if single }
\end{array}\right.
\end{aligned}
$$

2. Compute the interpersonally-comparable-metric utility of household $i$ under tax regime $R, \mu_{i}(R)$. Let $V^{0}\left(R_{0}\right)$ be the expected maximum utility attained by a reference household under a reference tax-transfer regime. In this paper we choose as reference household the poorest single and as reference tax-transfer system the current system:

$$
V^{0}\left(R_{0}\right)=\ln \left(\sum_{h} \exp \left\{V\left(R_{0}\left(w^{0} h, y^{0}\right), h, Z^{0} ; \theta, \gamma\right)+\sum_{k=1}^{4} \gamma_{k} D_{k}(h)\right\}\right)
$$

The interpersonally-comparable money-metric utility of household nunder tax regime $R, \mu^{n}(R)$, is then defined by:

$$
\ln \left(\sum_{h} \exp \left\{V\left(\mu^{n}(R), h, Z^{0} ; \theta, \gamma\right)+\sum_{k=1}^{4} \gamma_{k} D_{k}(h)\right\}\right)=V^{n}(R) .
$$

In other words, $\mu^{n}(R)$ is the net available income needed by the reference household under the reference tax-transfer regime in order to attain the same expected

22 For the derivation of the expression for the expected maximum utility see McFadden (1978) and BenAkiva and Lerman (1985). The same methodology for empirical welfare evaluation is used by Colombino (1998). 
maximum utility level of household $n$ under tax-benefit regime $R$ : it is analogous to the "equivalent income" as defined by King (1983).

3. Last, the four social welfare indexes are defined as follows:

$$
\begin{aligned}
& W(R)=\mu(R) \\
& G S W_{0}(R)=\mu(R)(1-I(R)) \\
& G S W_{1}(R)=\mu(R)\left(1-I(R)-p_{1}(R)\right) \\
& G S W_{2}(R)=\mu(R)\left(1-I(R)-p_{2}(R)\right)
\end{aligned}
$$

where

$$
\mu(R)=\frac{1}{N} \sum_{n} \mu^{n}(R),
$$

$I(R)$ is the Gini coefficient of the sample distribution of $\mu_{n}(R), p_{1}(R)$ is the headcount poverty ratio $=$ proportion of households below the poverty line. $p_{2}(R)$ is the poverty gap ratio $=($ head-count poverty ratio $) \times$ (average distance from the poverty line among the poor households).

$W(R)$ is the pure utilitarian criterion. $G S W_{0}(R)$ is the Gini Social Welfare function. $G S W_{1}(R)$ and $G S W_{2}(R)$ are poverty-augmented versions of $G S W_{0}(R)$. The social welfare indexes explicitly incorporate the efficiency-equity trade-off (a part from the pure utilitarian index $W(R)$ ). Efficiency is measured by $\mu(R)$, while Equity is alternatively measured by $1-I(R)$ or $1-I(R)-p_{1}(R)$ or $1-I(R)-p_{2}(R) .{ }^{23}$ By taking the logarithm of the social welfare function, we get an additive decomposition, i.e.

$$
\begin{aligned}
& \ln \left(G S W_{0}(R)\right)=\ln (\mu(R))+\ln (1-I(R)) \\
& \ln \left(G S W_{1}(R)\right)=\ln (\mu(R))+\ln \left(1-I(R)-p_{1}(R)\right) \\
& \ln \left(G S W_{2}(R)\right)=\ln (\mu(R))+\ln \left(1-I(R)-p_{2}(R)\right)
\end{aligned}
$$

In Sect. 6 we will exploit the above decomposition to identify the contribution of the reforms' attributes upon social welfare and its efficiency and equity components.

\section{Results}

Tables 4, 5 and 6 illustrate the results from different perspectives. In Table 4 the policies are ranked - the most preferred on top-according to the Social Welfare functions presented in Sect. 4. Each reform is identified by three pieces of information: the income support mechanism (CBI etc.), the Flat $(\mathrm{F})$ or Progressive $(\mathrm{P})$ tax rule and the coverage i.e. the value of $a(0.5,0.75$ or 1$)$ as defined in Sect. 3. For example, UBI + WS_F_0.75 denotes a policy where the income support mechanism is UBI + WS, the tax rule is Flat and $G=0.75 P \sqrt{N}$. Hereafter the comments to the results are organized along the five issues mentioned in the introduction.

23 See Aaberge (2007) for the generalization of the GSW and Atkinson (1987) for poverty-augmented social welfare functions. 


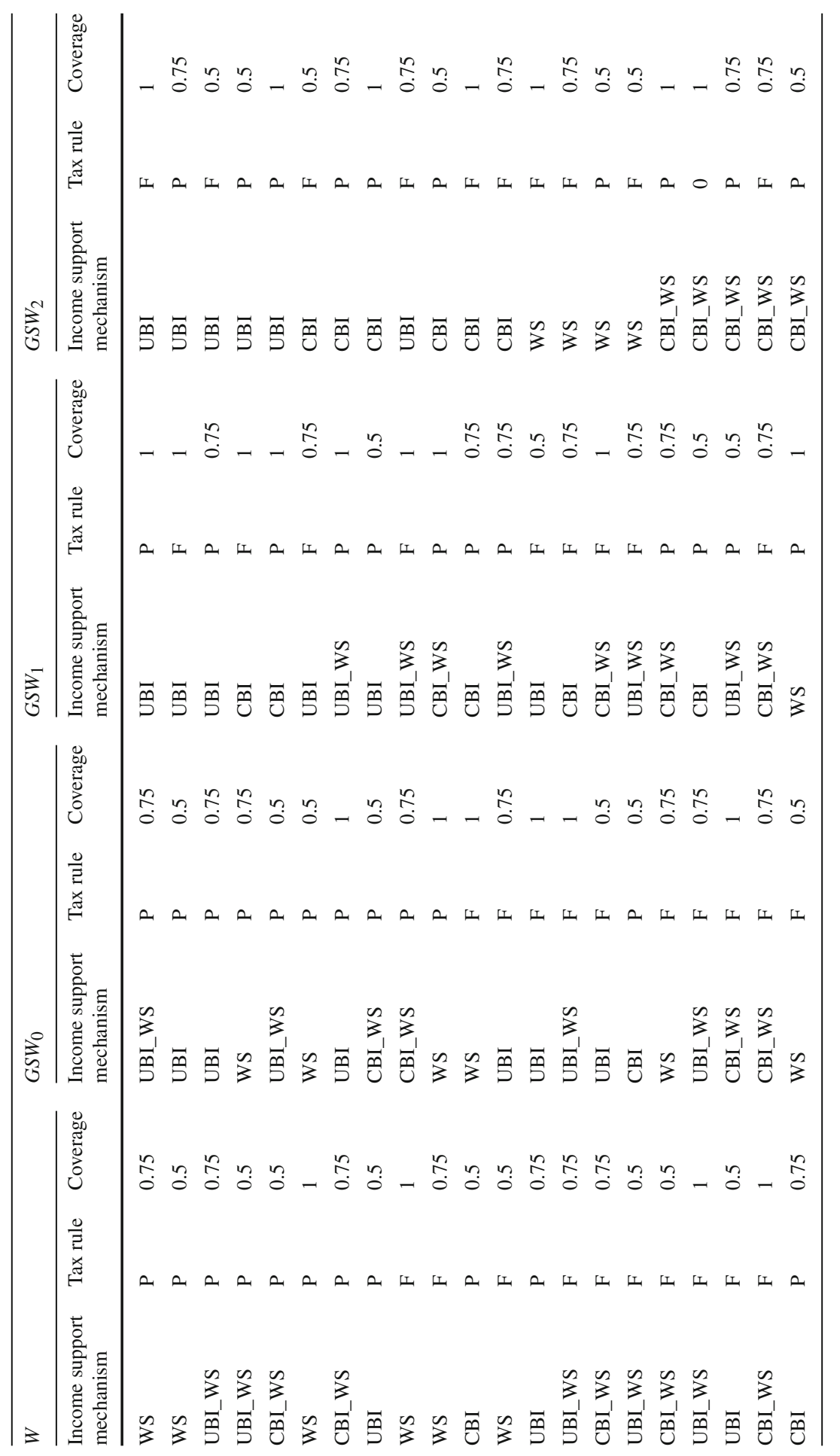




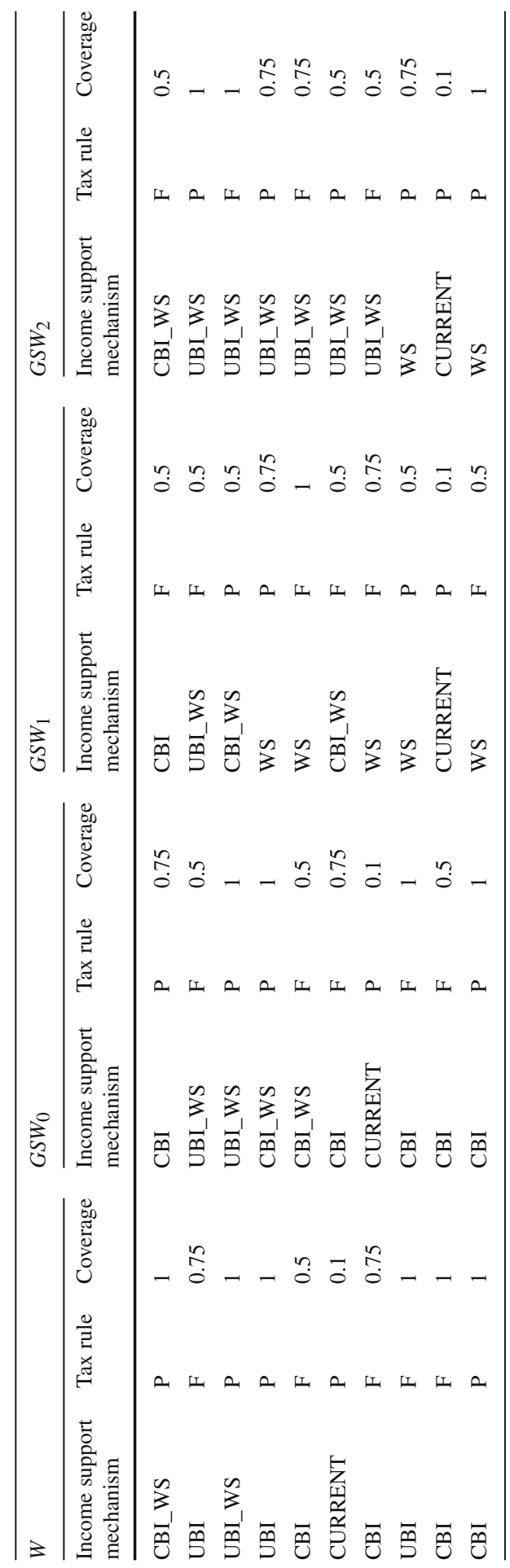


While the pure utilitarian criterion $W$ seems to favour WS-like mechanisms, under all the versions of the $G S W$ indexes the top positions in the rankings of Table 4 are taken by transfer-based mechanisms or by mixed policies envisaging both transfers and subsidies, with a prominence of unconditional vs. conditional policies. However, we observe important differences rankings produced by the three versions of the GSW criterion. $G S W_{0}$ favours the mixed policy UBI+WS or UBI together with Progressive taxes; $G S W_{1}$ and $G S W_{2}$ definitely promote UBI (or even CBI), with a less clear preference between Progressive or Flat Taxes. Under $\mathrm{GSW}_{0}$, the preferred coverage is $75 \%$, while under $G S W_{1}$ it is more often $100 \%$. Most reforms rank better, social welfare wise, than the current system under both social welfare criteria. The results are definitively in favour of universalistic reforms as compared with the current categorical policies. Of course, this does not imply that we could not design even better categorical policies: the question we are answering here is whether we can improve upon the current policies by moving towards universalism. In summary, according to the three versions of the GWS index, the indications for the best reform seem to converge upon UBI or UBI + WS.

A method to synthesize the effect of policy characteristics consists regressing the value of the social welfare indexes and (when relevant) of their equity components against a set of variables that measure the attributes of the tax-benefit systems. The results are reported in Table 5. The regressions help to identify the welfare contributions of policy attributes. A progressive tax rule contributes to social welfare and to its equity component under almost all the criteria. A contribution to this result comes from the pattern of wage elasticity of labour supply: higher income households are much less elastic than lower income ones. ${ }^{24}$ The exceptions are the equity components of $G S W_{0}$ (not significant effect) and of $G S W_{2}$. The effect of Coverage is estimated as non-linear with a concave profile. The effect is positive up to $\alpha=0.055$ under $W, \alpha=0.687$ under $G S W_{0}, \alpha=1.519$ under $G S W_{1}$ and $\alpha=0.794$ under $\mathrm{GSW}_{2}$. Unconditional policies have a positive effect everywhere. Transfers and subsidies tend to have effects of opposite signs. The former favour equity, the latter efficiency.

Table 6 shows the behavioural and fiscal effects of all the policies, including the current one. labour supply, income, top marginal tax rate required by fiscal sustainability, annual benefit received by the households, proportion of "winners", poverty ratio. As explained in Sect. 5.2, there might be (mild) differences among the fiscally neutral equilibrium allocation associated to the alternative social welfare criteria. Table 6 refers to the allocation associated to $G W S_{0}$. Table 6 helps to build a comprehensive picture of how each reform would impact on the economy, and moreover permits to evaluate the reforms according to criteria that are different from the one we adopted as the main criterion (i.e. social welfare).

Pure transfer-based policies have a mild impact on labour supply and a major impact on the poverty ratio. Under CBI, female (male) labour supply is on average 963 (1957) compared to 973 (1978) under the current system and analogously under UBI we get 956 (1960); however, CBI and UBI reforms bring down the poverty ratio respectively to 1.23 and 0.5 (compared to the "current" 4.23). WS reforms produce a modest increase

24 See for example Aaberge et al. (1999, 2004). A recent survey by Diamond and Saez (2011) gives support to the superiority of progressive taxes. 


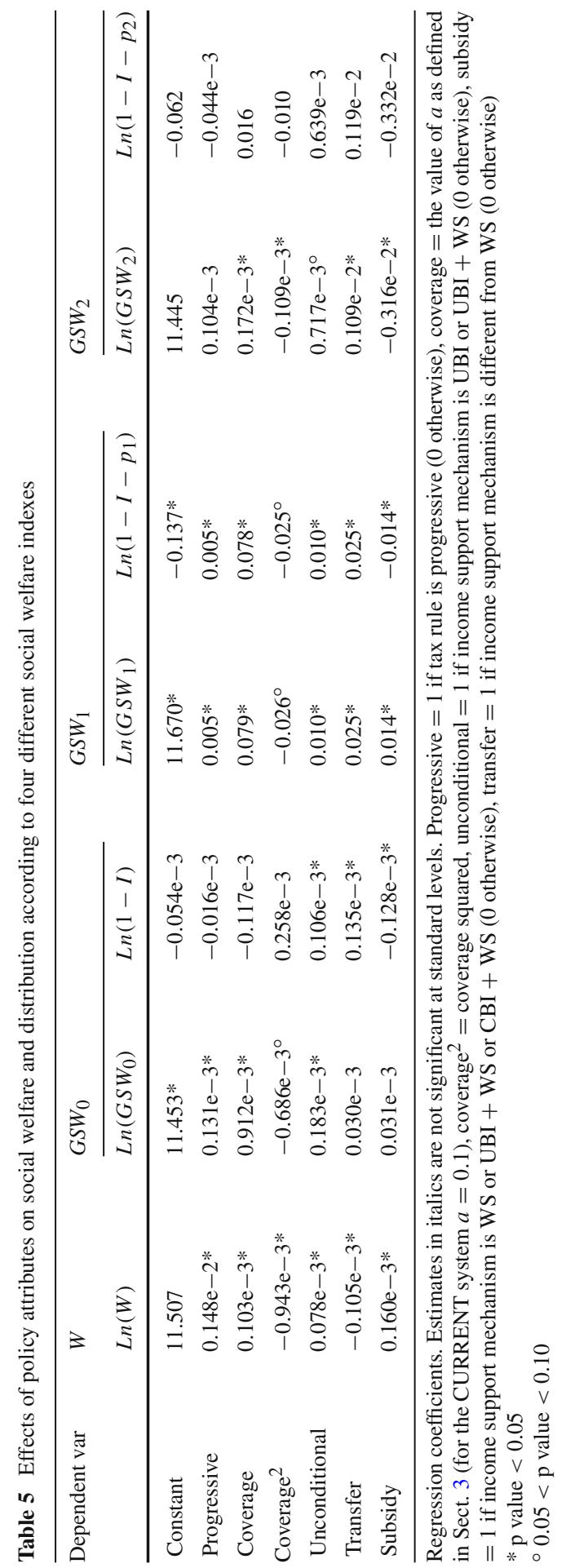




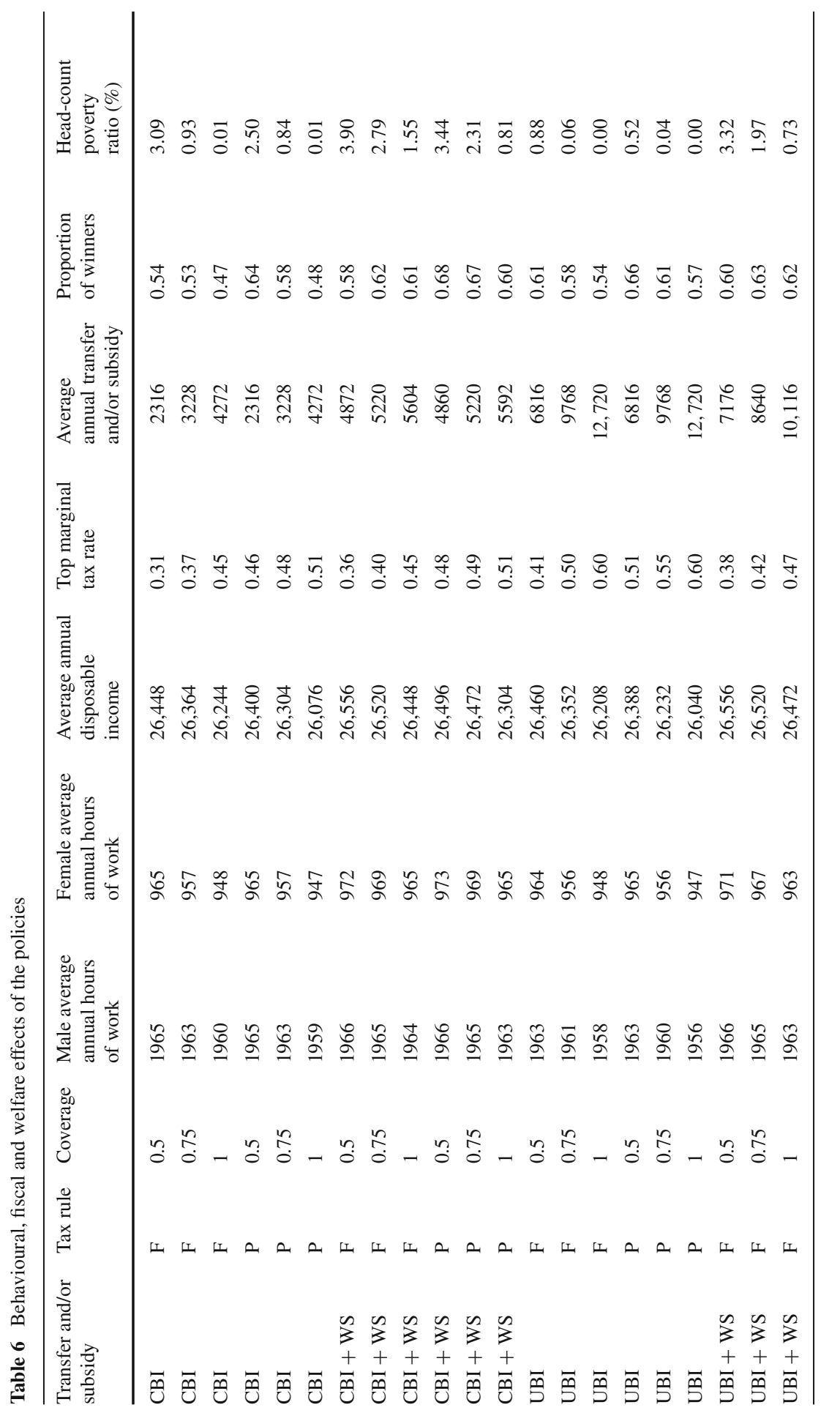




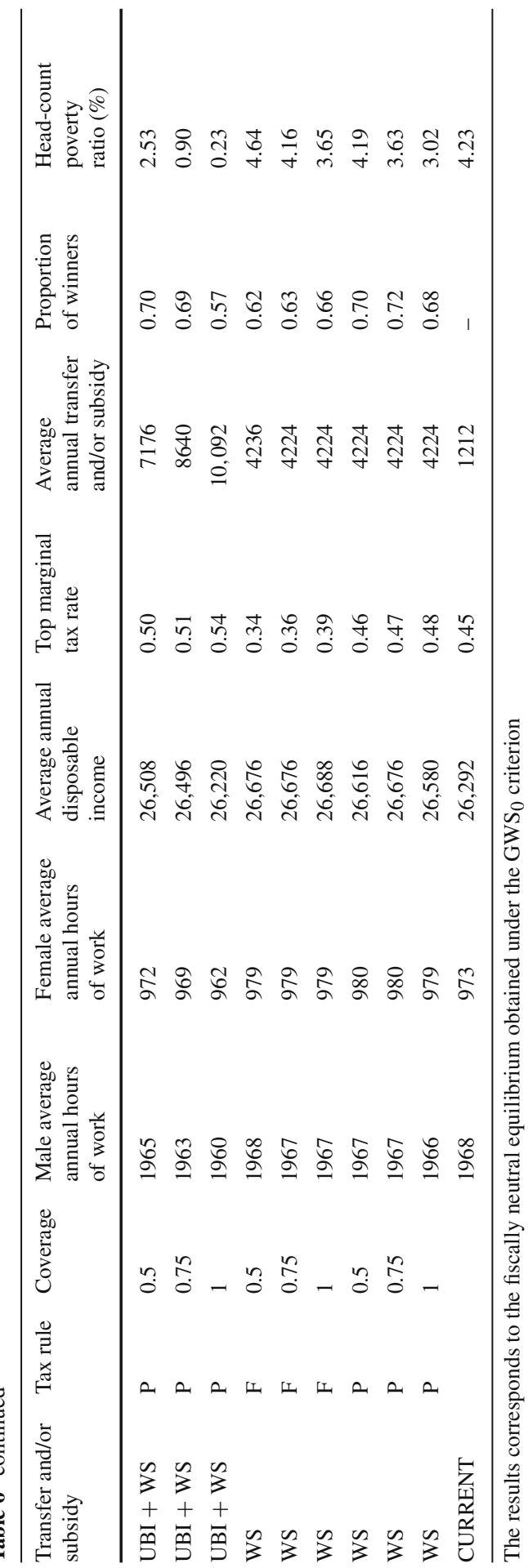


in female labour supply (around plus 6-7 h) but are much less effective in reducing the poverty ratio, which goes down from 4.23 to 3.88 . Mixed policies produce effects somewhat in between pure transfer and pure subsidy policies.

It is interesting to compare the effects on labour supply of unconditional v. conditional policies, taking into account the monetary benefits they provide to the households. According to the social welfare rankings (based on GSW-type criteria) of Table 4, unconditional systems (UBI or UBI + WS) are overall preferable to conditional ones. This result can be explained by observing (Table 6) that the greater generosity of the unconditional transfers is compensated by the lack of poverty-trap effects, with the following implications: UBI or UBI + WS policies provide on average an annual benefit of $€ 6433$ compared to $€ 4250$ provided by CBI or CBI + WS; at the same time, both unconditional and conditional policies induce essentially the same amount of labour; marginal tax rates required for fiscal neutrality are modestly higher for unconditional policies as compared to conditional ones; most important UBI or UBI + WS perform better in reducing poverty.

The top-winner reforms according to the GSW-type criteria envisage an average total annual benefit (comprehensive of transfer and-if present-subsidy) per household of $€ 8640$ (about $70 \%$ of the average household-specific poverty line) for UBI + WS_P_0.75 and $€ 12720$ (about $100 \%$ of the average household-specific poverty line) for UBI_P_1 and UBI_F_1. These amounts are to be compared with the $€ 1212$ of the CURRENT system. ${ }^{25}$

With the exceptions of CBI_F_1 and CBI_P_1 all the reforms imply a percentage of winners above $50 \%$ and would therefore win a referendum against the CURRENT system.

The reforms are more expensive than the current policy. They are financed through three channels: replacing the current policy, enlarging the tax base to make it comprehensive of all income and adjusting the marginal tax rates on personal incomes. All the reforms envisaging progressive taxation require an increase of marginal tax rates. UBI + WS_P_0.75 requires an $11 \%$ increase of the current (1998) marginal tax rates, which means a $51 \%$ top marginal tax rate. Under the same scenario, UBI_P_1 requires a $60 \%$ top marginal tax rate. These figures are high but not at all unrealistic. For example in 2009 the top marginal tax rates in Denmark and Sweden were respectively around 62 and $57 \%$. If the above tax rates were judged, for some reason (possibly from the point of view of political consensus), to be not feasible, it should be noticed that the mеnи of welfare improving reforms is very large. For example, the flat version UBI + WS_F_0.75 would require a $42 \%$ flat rate. Therefore, we are left with many reforms to choose among according to different criteria or constraints. The level of the marginal tax rates is probably one of the issues of greatest concern for the policy makers. The results provided by Table 6 can help complementing the ranking based on social welfare with additional constraints. For example, if we require that the reforms should not imply a top marginal tax rate greater than 0.45 (= current top marginal tax rate), then all the reforms with progressive tax rule have to be dropped from

\footnotetext{
25 The $€ 1212$ transfer in the CURRENT system is just the average of the (expected) categorical, conditional or local transfers and benefits (such as unemployment benefits, cassa integrazione, family benefits etc.).
} 
the rankings of Table 4: a progressive tax rule could only be sustained with additional fiscal channels, e.g. taxes on wealth and/or consumption.

\section{Conclusions}

We used a microeconometric model of labour supply and a social evaluation methodology in order to identify feasible and welfare-improving universalistic income support mechanisms in Italy. We considered five type of mechanism: CBI, UBI, WS, CBI + WS and UBI + WS. Each one has three variants, depending on the degree of coverage with respect to the poverty line: 50,75 and $100 \%$. Moreover, each type can be coupled either with Flat tax rule or with a Progressive Tax rule. In total, we have $5 \times 3 \times 2=30$ possible reforms. The tax parameter (either the constant rate in the Flat Tax rule or the proportional change in the marginal tax rates with respect to the current (1998) system in the Progressive Tax rule) is determined endogenously so that the total net tax revenue remains as under the current system. The simulation adopts a methodology that allows for market equilibrium and ensures a consistent comparative statics interpretation of the simulation results. Under the pure Gini Social Welfare criterion, the best policy is an unconditional basic income coupled with a wage subsidy (amounting to a total benefit close to $75 \%$ of the Poverty Level), while under the Poverty-Adjusted Gini criteria the best policy is a pure unconditional transfer equal to (or possibly greater than) the Poverty Level. Overall, provided some weight is given to equity, unconditional policies appear to rank better than conditional (means tested) ones. Evaluation criteria different from the ones chosen in this exercise might of course dictate a different ranking of the policies and different features of the best ones. The set of policies that are preferable to the current system is very large and suggests the possibility of selecting a universalistic best reform according to many different criteria and constraints.

It is not easy to evaluate the results presented in this paper as compared to the overall empirical literature on income support mechanisms. While the research on means-tested policies and tax credits (or wage subsidies) is abundant, so far there are not many microeconometric or microsimulation analyses of unconditional policies. Examples are Scutella (2004) for Australia, Clavet et al. (2013) for Canada and Horstschräer et al. (2010) and Jensen et al. (2014) for Germany. As to Canada and Germany, the focus of the studies is on labor supply effects; the study on Australia adopts also a social welfare criterion. While in the first three exercises he reduction in labor supply (for secondary workers) is found to be larger than in the Italian case, the study of Jensen et al. (2014) finds positive effects on labour supply (and welfare) of a system of the UBI + FT type. Besides differences in labor market institutions and possibly in preferences, differences in modeling approach may also explain part of these differences in labor supply effects. In the first three studies, the negative effects on labour supply are serious enough to raise doubts about the viability of unconditional basic income-like policies. However, these studies do not constrain the policy parameters to guarantee fiscal neutrality. Yet, the Australian study reveals that unconditional basic income might be social welfare enhancing despite the reduction in labor supply. A different source of empirical evidence is provided by local implementations and experiments (Pasma 2014; Widerquist 2005). Blattman et al. (2013) describes 
an experiment in Uganda illustrating the positive incentives that can be activated by unconditional cash transfers. Other studies exploit the data produced by natural experiments or quasi-experiments. For example, Imbens et al. (1999) and Marx and Peeters (2008) investigate the effects of exogenous changes in unearned income by analyzing the behaviour of lottery winners: the evidence suggests that the "unconditional" payoff does not have significant negative effects on labour supply. Akee et al. (2010) study the positive effects of a local implementation of unconditional transfers in Cherokee, North Carolina.

The data used for estimating and simulating the model were collected before the "Great Recession". In particular, the poverty rates reported in Table 6 are lower than the ones currently prevailing, both because of the survey year and because of the segment of population covered by the survey. It is therefore important to discuss the extent to which the results can be expected to carry over to the current scenario. The main issue is whether, in a scenario with fewer of jobs and lower incomes, the ranking of policies would be significantly different from what reported in this paper. We think it would not, in particular if we focus upon the comparison of conditional vs. unconditional policies-potentially the most controversial issue among those addressed by our exercise. In a recession, the number of market jobs and the level of earnings is lower. The consequence is that the costs of means-tested policies would increase, but the costs of unconditional policies would remain the same. Therefore, unconditional policies would probably rank even better relative to means-tested policies.

Acknowledgments This paper uses EUROMOD for computing the budget constraints under the current tax-benefit system when preparing the data set for estimating the microeconometric model. EUROMOD is a tax-benefit microsimulation model for the European Union that enables researchers and policy analysts to calculate, in a comparable manner, the effects of taxes and benefits on household incomes and work incentives for the population of each country and for the EU as a whole. EUROMOD was originally designed by a research team under the direction of Holly Sutherland at the Department of Economics in Cambridge, UK. It is now developed and updated at the Microsimulation Unit at ISER (University of Essex, UK). Edlira Narazani, Marilena Locatelli and Flavia Coda Moscarola, research assistants at the Department of Economics and Statistics "Cognetti De Martiis", have contributed to various stages of this work by performing econometric estimations, statistical tests and policy simulations. Financial support by the Compagnia di San Paolo is gratefully acknowledged.

\section{Appendix}

This Appendix provides a detailed descriptions of the reforms by specifying net available income as a function of taxable income. The symbols used are defined as follows. $x_{F}=w_{F} h_{F}$ is the female gross earnings; $x_{M}=w_{M} h_{M}$ is the male gross earnings;

$$
x=x_{F}+x_{M}
$$

$y_{F}$ is the female unearned gross income; $y_{M}$ is the male unearned gross income; $m$ is the other household net income; $S_{F}$ is the social security contributions (female); $S_{M}$ is the social security contributions (male);

$$
S=S_{F}+S_{M} ;
$$


$I_{F}=g_{F}+y_{F}-S_{F}$ is the taxable income (female); $I_{M}=g_{M}+y_{M}-S_{M}$ is the taxable income (male);

$$
I=I_{F}+I_{M}
$$

$P$ is the poverty line; $N$ is the number of people in the household; $G$ is the $\alpha P \sqrt{N}$ with $\alpha=1,0.75,0.50 ; C_{F}$ is the net available income (female); $C_{M}$ is the net disposable income (male);

$$
C=m+C_{F}+C_{M}
$$

$T$ is the taxes paid by the household; $B$ is the benefits or transfers received by household; $\mathrm{q}$ is the average propensity to consumption; $r$ is the average VAT rate; $\omega$ is the proportional subsidy on the gross wage rate; $\phi($.$) is the progressive tax function:$ it applies the 1998 marginal tax rates multiplied by a constant such that the fiscal neutrality constraint is satisfied, i.e.

$$
\sum T^{1}-\sum B^{1}+r \sum q C^{1}+\sum S^{1}=\sum T^{0}-\sum B^{0}+r \sum q C^{0}+\sum S^{0}
$$

where the superscript $\mathrm{R}$ denotes a generic reform and the superscript 0 denotes the current (1998) system.

The current (1998) marginal tax rates are as follows:

\begin{tabular}{ll}
\hline Income brackets & Marginal tax rates \\
\hline $0-7.7$ & 18 \\
$7.7-15.5$ & 26 \\
$15.5-31$ & 33 \\
$31-69.7$ & 39 \\
$>69.7$ & 45 \\
\hline
\end{tabular}

Income brackets (originally in Italian Lire) are expressed in thousands of euros.

Under the 1998 system the above rates are applied to personal earnings, together with deductions, allowances and benefits. Under the reforms all deductions, tax credits and benefits are cancelled, the income brackets are kept unchanged and the marginal tax rates (either the flat or the progressive ones) are applied to the whole personal income (not just to earnings). 


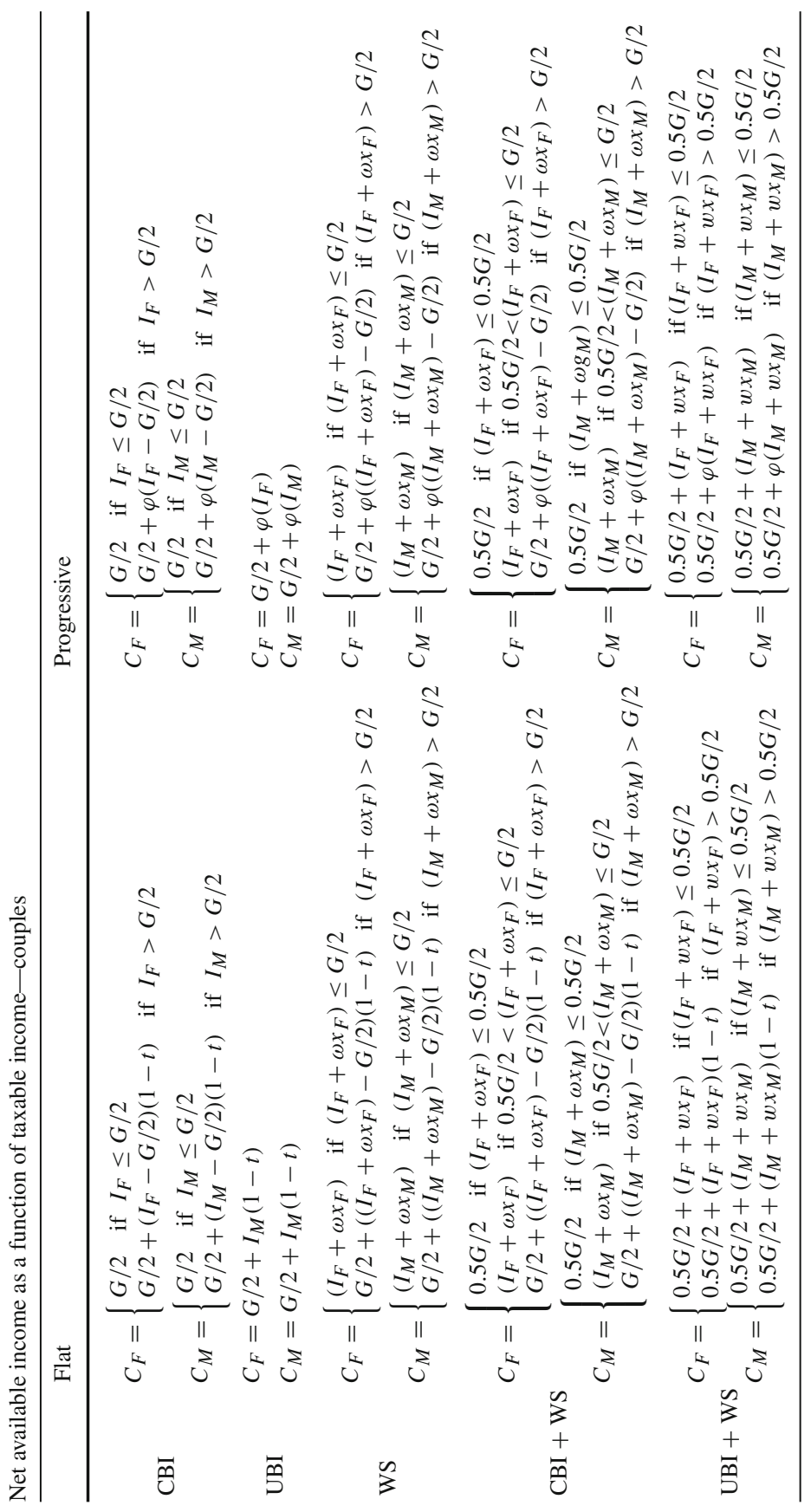




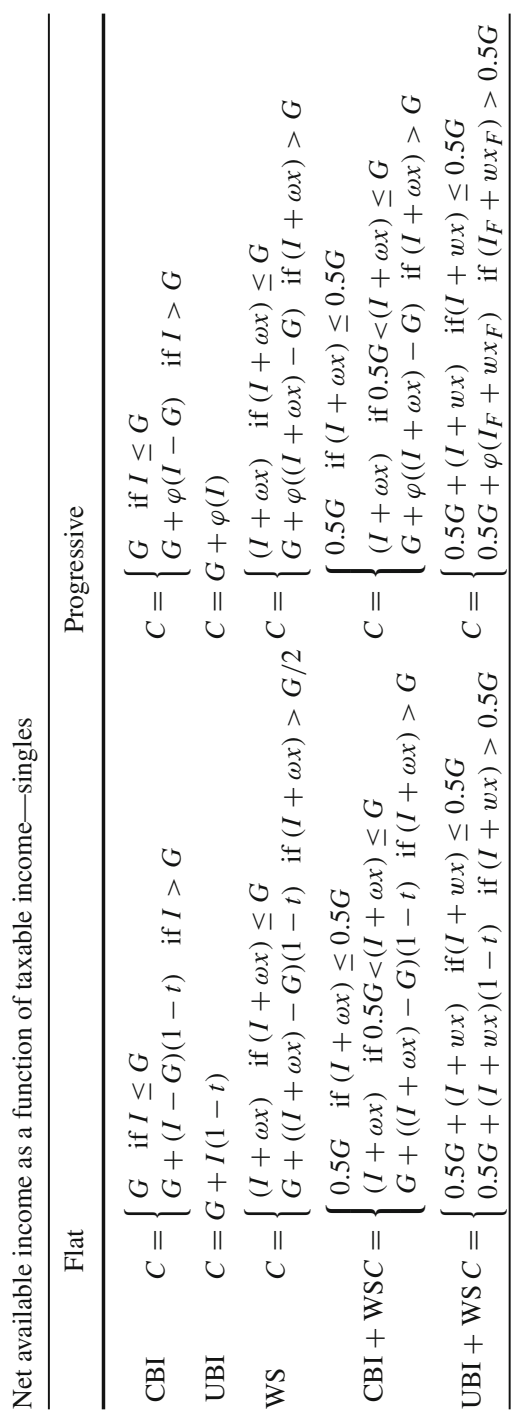




\section{References}

Aaberge R (2007) Gini's nuclear family. J Econ Inequal 5(3):305-322

Aaberge R, Colombino U (2006) Designing optimal taxes with a microeconometric model of labour supply. In: IZA discussion paper no. 2468

Aaberge R, Colombino U (2012) Accounting for family background when designing optimal income taxes: a microeconometric simulation analysis. J Popul Econ 25(2):741-761

Aaberge R, Colombino U (2013) Designing optimal taxes with a microeconometric model of labour supply. Scand J Econ 115(2):449-475

Aaberge R, Colombino U (2014) Labour supply models. In: O’Donoghue C (ed) Handbook of microsimulation modelling, contributions to economic analysis, vol 293. Emerald

Aaberge R, Flood L (2008) Evaluation of an in-work tax credit reform in Sweden: effects on labor supply and welfare participation of single mothers. In: IZA discussion paper no. 3736

Aaberge R, Colombino U, Strøm S (1999) Labor supply in Italy: an empirical analysis of joint household decisions, with taxes and quantity constraints. J Appl Econ 14(4):403-422

Aaberge R, Colombino U, Strøm S (2000) Labour supply responses and welfare effects from replacing current tax rules by a flat tax: empirical evidence from Italy, Norway and Sweden. J Popul Econ 13(4):595-621

Aaberge R, Colombino U, Strøm S (2004) Do more equal slices shrink the cake? An empirical evaluation of tax-transfer reform proposals in Italy. J Popul Econ 17(4):767-785

Aaberge R, Colombino U, Wennemo T (2009) Evaluating alternative representations of the choice sets in models of labour supply. J Econ Surv 23(3):586-612

Aaberge R, Dagsvik J, Strøm S (1995) Labour supply responses and welfare effects of tax reforms. Scand J Econ 97(4):635-659

Akee R, Copeland W, Keeler G, Angold A, Costello E (2010) Parents' incomes and children's outcomes: a quasi-experiment using transfer payments from casino profits. Am Econ J Appl Econ 2(1):86-115

Alleanza contro la povertà in Italia (2014) Reddito di inclusione sociale. http://www.redditoinclusione.it/ wp-content/uploads/2014/10/REIS_completo_web_2014.pdf

Atkinson AB (1987) On the measurement of poverty. Econometrica 55:749-764

Atkinson AB (1995) Public economics in action. Clarendon Press, Oxford

Atkinson AB (2011) Basic income: ethics, statistics and economics. Nuffield College, Oxford. http://www. nuff.ox.ac.uk/users/atkinson/Basic_Income\%20Luxembourg\%20April\%202011.pdf

Atkinson AB (2015) Inequality. What can be done. Harvard University Press, Cambridge

Baldini M, Toso S (2013) Sostegno del reddito e lotta alla povertà in Italia: le politiche pubbliche in tempo di crisi. Centro di Analisi delle Politiche Pubbliche, paper n 104

Baldini M, Bosi P, Toso S (2002) Targeting welfare in Italy: old problems and perspectives of reform. Fiscal Stud 23:51-75

Barrientos A, Lloyd-Sherlock P (2002) Non-contributory pensions and social protection. In: Discussion paper no. 12. Issues in social protection. ILO, Geneva

Ben-Akiva M, Lerman SR (1985) Discrete choice analysis. The MIT Press, Cambridge

Berton F, Richiardi M, Sacchi S (2009) Flex-insecurity. Il Mulino, Bologna

Besley T (1990) Means testing versus universal provision in poverty alleviation programmes. Economica 57(225):119-129

Bin I (ed) (2012) Reddito Minimo Garantito. Edizioni Gruppo Abele, Torino

Blattman C, Fiala N, Martinez S (2013) Credit constraints, occupational choice, and the process of development: long run evidence from cash transfers in Uganda. http://ssrn.com/abstract=2268552

Blundell R, Shephard A (2012) Employment. Hours of work and the optimal taxation of low-income families. Rev Econ Stud 79(2):481-510

Blundell R, Brewer M, Haan P, Shephard A (2009) Optimal income taxation of lone mothers: an empirical comparison for Britain and Germany. Econ J 119(535):F101-F121

Boeri T, Perotti R (2002) Meno pensioni, più welfare. Il Mulino, Bologna

Brady D, Beckfield J, Seeleib-Kaiser M (2005) Economic globalization and the welfare state in affluent democracies, 1975-1998. Am Sociol Rev 7:921-948

Brynjolfsson E, McAfee A (2014) The second machine age. Work, progress and prosperity in a time of brilliant technologies. W. W. Norton \& Company, New York

Busilacchi G (2013) Welfare e diritto al reddito. Le politiche di reddito minimo nell'Europa a 27. FrancoAngeli, Milano 
Bryan J (2005) Have the 1996 welfare reforms and expansion of the earned income tax credit eliminated the need for a basic income guarantee in the US? Rev Soc Econ 63(4):595-611

CIES (2012) Rapporto sulle politiche contro la povertà e l'esclusione sociale_Anni 2011-2012. Ministero del Lavoro e delle Politiche Sociali

Clavet N, Duclos J, Lacroix G (2013) Fighting poverty: assessing the effect of guaranteed minimum income proposals in Quèbec. In: Discussion paper no. 7283. IZA, Bonn

Colombino U (1998) Evaluating the effects of new telephone tariffs on residential users' demand and welfare. A model for Italy. Inf Econ Policy 10(3):283-303

Colombino U (2013) A new equilibrium simulation procedure with discrete choice models. Int J Microsimul $6(3): 25-49$

Colombino U, Locatelli M, Narazani E, O’Donoghue C (2010) Alternative basic income mechanisms: an evaluation exercise with a microeconometric model. Basic Income Stud 5(1)

Colonna F, Marcassa S (2012) Taxation and labor force participation: the case of Italy. In: CEPREMAP working papers (Docweb) 1203

Cowen T (2013) Average is over: powering America beyond the age of the great stagnation. Penguin Publishing Group

Dagsvik J (2000a) Aggregation in matching markets. Int Econ Rev 41(1):27-57

Dagsvik J (2000b) Multinomial choice and selectivity. In: Discussion papers 264, Research Department of Statistics Norway

Dagsvik J, Strøm S (2006) Sectoral labour supply, choice restrictions and functional form. J Appl Econ 21(6):803-826

De Luca G, Rossetti C, Vuri D (2012) In-work benefit policies for Italian married couples: design and labor supply effects. In: IZA discussion paper no. 6739

De Vincenti C, Paladini R (2009) Personal income tax design for Italy: lessons from the theory. Riv Ital Econ XIV 1:7-46

Diamond P (1998) Optimal income taxation an example with a U-shaped pattern of optimal marginal tax rates. Am Econ Rev 88:83-95

Diamond P, Saez E (2011) The case for a progressive tax: from basic research to policy recommendations. In: CesIfo WP no. 3548

Esping-Andersen G (1990) The three worlds of welfare capitalism. Polity Press, Cambridge

Fang H, Keane M (2004) Assessing the impact of welfare reform on single mothers. Brook Papers Econ Activity 1:1-116

Ferrera M, Fargion V, Jessoula M (2012) Alle radici del welfare all'italiana, Marsilio

Figari F (2011) From housewives to independent earners: can the tax system help Italian women to work? In: ISER working paper no. 2011-15

Fortin B, Truchon M, Beausenjour L (1993) On reforming the welfare system. Workfare meets the negative income tax. J Public Econ 51(2):119-151

Francesconi M, Rainer H, Van der Klaauw W (2009) The effects of in-work benefit reform in Britain on couples: theory and evidence. Econ J 119(535):F66-F100

Friedman M (1962) Capitalism and freedom. University of Chicago Press, Chicago

Frazer H, Marlier E (2009) Minimum income schemes across EU members. European Commission DG Employment

Haan P, Wrohlich K (2007) Optimal taxation: the design of child related cash- and in-kind-benefits. In: IZA discussion papers 3128

Handler JF, Babcock AS (2006) The failure of workfare: another reason for a basic income guarantee. Basic Income Stud 1(1):1-22

Horstschräer J, Clauss M, Schnabel R (2010) An unconditional basic income in the family context: labor supply and distributional effects. In: Discussion paper no. 10-091. ZEW Center for European Economic Research. http://econstor.eu/bitstream/10419/42222/1/64028048X.pdf

Hughes JJ (2014) A strategic opening for a basic income guarantee in the global crisis created by AI, robots, desktop manufacturing and biomedicine. J Evol Technol 24(1):45-61

Kalb G (2000) Accounting for involuntary unemployment and the cost of part-time work. In: Working paper no. BP-35. Centre of Policy Studies, Monash University, Australia

King M (1983) Welfare analysis of tax reforms using household data. J Public Econ 21:183-214

Kornstad T, Thoresen T (2007) A discrete choice model for labor supply and childcare. J Popul Econ 20(4):781-803 
Krugman P (2013) Sympathy for the luddites. The New York Times, 13 June 2013. http://www.nytimes. com/2013/06/14/opinion/krugman-sympathy-for-the-luddites.html?_r=0

Imbens G, Rubin D, Sacerdote B (1999) Estimating the effect of unearned income on labor supply, earnings, savings and consumption: evidence from a survey of lottery players. In: Working paper no. 7001. NBER, Cambridge

Immervoll H, Kleven HJ, Kreiner CT, Saez E (2007) Welfare reforms in European countries: a microsimulation analysis. Econ J 117(1):1-44

Jansova E, Venturini GL (2009) Pathways of income protection. Ideal-typical configurations of minimum income scheme in the European Union. In: Presentation at the future of the welfare state: paths of social policy innovation between constraints and opportunities, Urbino, 17-19 September 2009

Jensen R, Rostam-Afschar D, Steiner V (2014) Getting the poor to work: three reforms for a busy Germany. Mimeo. http://davud.rostam-afschar.de/cv/cv.pdf

Marchant GE, Stevens YA, Hennessy JM (2014) Technology, unemployment \& policy options: navigating the transition to a better world. J Evol Technol 24(1):26-44

Marx A, Peeters H (2008) An unconditional basic income and labor supply: results from a pilot study of lottery winners. J Socio Econ 37(4):1636-1659

McFadden D (1974) Conditional logit analysis of qualitative choice behavior. In: Zarembka P (ed) Frontiers in econometrics. Academic Press, New York

McFadden D (1978) Modelling the choice of residential location. In: Karlquist A, Lundquist L, Snickard F, Weilbull JJ (eds) Spatial interaction theory and planning models. North-Holland, Amsterdam

Meade J (1993) Liberty, equality and efficiency. Apologia pro Agathopia Mea, McMillan, London

Meghir C, Phillips D (2008) Labour supply and taxes. Institute for Fiscal Studies, WP 08/04

Mistero del Lavoro e delle Politiche Sociali (2014) Verso la costruzione di un istituto nazionale di contrasto alla povertà. http://www.lavoro.gov.it/Priorita/Documents/Relazione_povert\%C3\%A0_ 18settembre2013.pdf

Mirlees JA (1971) An exploration in the theory of optimal income taxation. Rev Econ Stud 38(2):175-208

Negri N, Saraceno C (1996) Le politiche contro la povertà in Italia. Il Mulino, Bologna

Onofri P (ed) (1997) Relazione finale della Commissione per l'analisi delle compatibilità macroeconomiche della spesa sociale. Presidenza del Consiglio dei Ministri, Roma

Pasma C (2014) Basic income programs and pilots. Basic Income Canada Network. http://www.thebigpush. net/uploads/2/2/6/8/22682672/basic_income_programs_and_pilots_february_3_2014.pdf

Perazzoli G (2014) Contro la miseria. Viaggio nell'Europa del Nuovo Welfare, Laterza

Rodrik D (1998) Why do more open economies have bigger governments? J Polit Econ 106:997-1032

Sacchi S (2005) Reddito minimo e politiche di contrasto alla povertà in Italia. Riv Dirit Sicur Soc 4:467-509

Sachs JD, Kotlikoff LJ (2012) Smart machines and long term misery. In: Working paper no. 18629. NBER, Cambridge

Sadka E, Garfinkel I, Moreland K (1982) Income testing and social welfare: an optimal tax-transfer model. In: Garfinkel I (ed) Income tested transfer programs: the case for and against. Academic Press, New York

Saez E (2001) Using elasticities to derive optimal income tax rates. Rev Econ Stud 68:205-229

Saez E (2002) Optimal income transfer programs: intensive versus extensive labor supply responses. Q J Econ 117(3):1039-1073

Saraceno C (2013) Il welfare. Il Mulino, Bologna

Scutella R (2004) Moves to a basic income-flat tax system in Australia: implications for the distribution of income and supply of labour. Melbourne Institute of Applied Economic and Social Research. http:// www.melbourneinstitute.com/downloads/working_paper_series/wp2004n05.pdf

Spence M (2011) Globalization and unemployment: the downside of integrating markets. Foreign Affairs. http://www.foreignaffairs.com/articles/67874/michael-spence/globalization-and-unemployment

Standing G (2008) How cash transfers promote the case for basic income. Basic Income Stud 3(1), article 5

Standing G (2011) The precariat: the new dangerous class. Bloomsbury Academic Press, London

Standing G (2012) Responding to the crisis: economic stabilization grants. Policy Polit 39(1):9-25

Tobin J (1966) The case for an income guarantee. Public Interest 15:31-41

Van Parijs P (1995) Real freedom for all. Oxford University Press, Oxford

Van Soest A (1995) Structural models of family labour supply. J Hum Resour 30(1):63-88

Van Trier W (1995) Every one a king. Department of Sociology, Katholieke Universiteit Leuven, Leuven

Van de Walle D (1999) Public spending and the poor. In: Policy research working papers, World Bank. doi:10.1596/1813-9450-1476 
Vermeulen F (2006) A collective model for female labour supply with non-participation and taxation. J Popul Econ 19(1):99-118

VV. AA. (2014) Il bilancio della crisi. Le politiche contro la povertà in Italia, Caritas

Widerquist K (2005) A failure to communicate: what (if anything) can we learn from the negative income tax experiments? J Behav Exp Econ 34(1) 